\title{
XIV.
}

\section{Ueber die Behandlung der Blattern und Abdominatyphen; ein Relief des Gegensätzlichen in Geist und Uebung der Heilkunde zu dem Typus der Gewerbe.}

\author{
Schismatisches Sendschreiben an Herrn Professor Rudolf Virchow. \\ Von Dr. Joseph Heine, \\ Kreismedicinalrath der plak zu Speyer.
}

(Hierzu Taf. XII.)

Inhalt: Die augenscheinliche Heilkraft des Quecksilbersublimates als Umsehlag in den Anfangsstadien der petechialen Blattern - die statistisch eclatante in den confluirenden und sonstigen von schwerem Fieber begleiteten. - Lichtblicke auf die organischen Heilungsbahnen und raschen Krisen des Abdominaltyphus durch das Gitter der nämlichen Sublimatbebandlung. - Unvereinbarkeit dieser Thatsachen mit den zeitlichen Doctrinen. - Sublimat, ein lieizmittel zu neuen Studien der Herzthätigkeit. - Heilkunde und Gewerbe; bizarrer Contrast zwischen der immanent-idealen und modern gesetzlichen Bestimmung jener.

$$
\text { "fat to capo ha." }
$$

Es ist die Richtung Ihrer Zeitschrift nicht, sich mit practisch therapeutisehen Dingen näher zu befassen. Allein die weitverbreitete, zeitliche Blatternnoth, theilweise von enormer Sterblichkeit z. B. in Berlin selbst, wofür unsere gebräuchliche Therapie sichtlich keinen Rath weiss, gäbe an und für sich ein philanthropisches Moment $a b$, von der gewöhnlichen Richtschnur abzuweichen. Wenn aber, wie sich zeigen wird, die heilsame Wirkung eines mächtigen Gegenmittels, oder besser gesagt, eines verrufenen Giftes in einer entschieden blutzersetzenden Krankheit, als welche die petechiale Form der Blattern von vornherein und secundär die confluirende Form durch das pyämisctue Moment sich erweisen, schlechterdings den bisherigen Anschauungsweisen und toxikologischen Versuchen zuwiderläuft, dann tritt das Thema aus dem rein practischen Bereiche in die Competenz der induetiven Theorie. Für Ihre Zeitschrift liegt hier eine Rechnung mit jrrationalen Grössen vor. Denn etwas Sonderbareres dürfte, als reines Experiment genomnen, kaum in der Medicin gedacht werden, als dass auf Einwickelungen der 
petechialen Hautstellen mit einer starken Lösung von Quiecksilbersublimat, welchem sonst mit Recht eine Art von scorbutischer Nachwirkung zugemessen wird, dieser ominöse Charakter binnen 48 bis 70 Stunden verschwindet, und die normale Pustelbildung dort and an den übrigen Körperstellen auf das förderlichste vor sich geht. Diese Thatsache ist auf Grund meiner zahlreichen spitälischen Versuche zweifellos, und macht die Abschätzung der Rettungen bei dieser Form höchst einfach, weil jedẹr erfahrene Blatternarzt das Proscenium wie die Intercurrenz der Petechien oder grösserer Blutextravasate als ein lethales Symptom zu betrachten pflegt. Der Erfolg gilt jedoch nach meinen bisherigen Erfahrungen nur von solchen kleineren oder grösseren petechialen Extravasaten, welche erst 24-48 Stunden auf der Haut steben. Gewöbnlich will dabei die Pustelbildung nicht recht vorwärts, und zeigt sich, mögen die Stippchen oder die Petechien die erste Erscheinung gewesen sein, verkümmert, wenn auch noch so zahılreich. Auch zähle jch unter meinen 17 Fällen keinen, wo die Petechien über die ganze Haut verbreitet gewesen wären, wohl aber an verschiedenen Stellen, welche zusammengestellt $\frac{1}{4}-\frac{1}{12}$ der gesammten Hautaberfläche eingenommen hätten. Einer darunter bekam anfangs eine wahre Blutbeule in den Achselhöhlen, das einzige grössere Extravasat unter meinen Beobachtungen. Nicht umsonst babe ich obigen Vorbehalt gemacht, weil diese Behandlung erst in den jüngsten Tagen an einer pastösen Frau von 25 Jahren sich erfolglos zeigte, welche angeblich etwas mehr als 48 Stunden vom erst bemerkten Ausbruche an mit zahllosen Blatternstippchen und verhältnissmässig sparsamen Petechien behaftet, dafür aber in ihrer ganzen Haut mit einem lividen Schimmer gleichsam getüncht war. Auch an spontanen Blutungen aus inneren Höhlen hatte keiner bis dahin gelitten und während der Behandlung anderer Formen sind später niemals Petechien zum Vorschein gekommen. Bei dieser Zählung sind darum solche ausgeschlossen, deren vollständig gereifte Pusteln im Eiterungs- oder gegen das Eintrocknungsstadium hin sich mehr oder weniger streckenweise namentlich an den Extremitäten, Zehen und Fingern mit Blut füllten, denu diese Art wurde mehr auf Rechnung von lokal-mechanischen Ursachen gesetzt und lediglich aus Vorsicht, namentlich bei lividerem Teint der umgebenden Haut, Einwickelung gebraucht. Vergleichsweise zu diesen stupenden Wahr- 

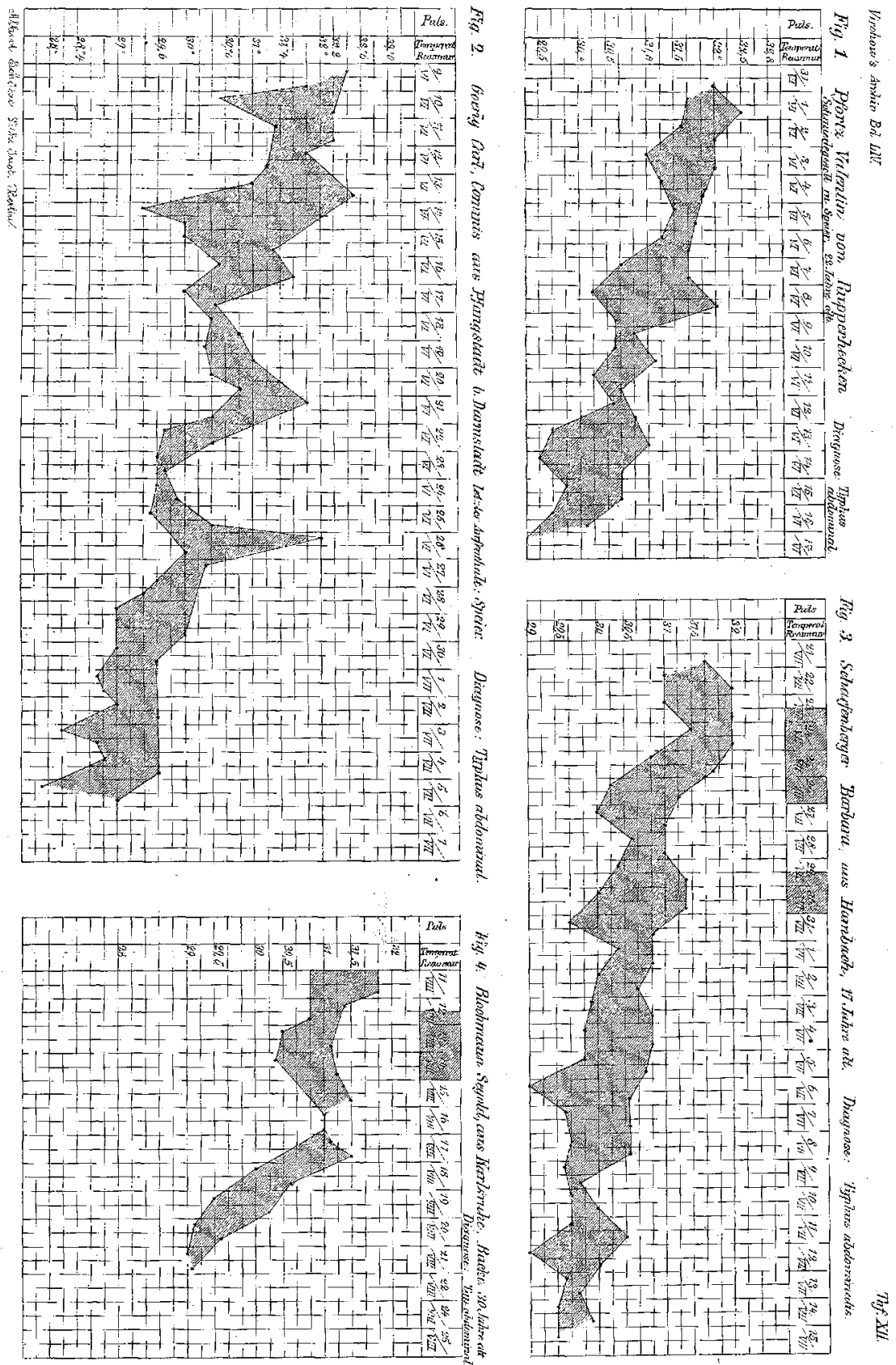
nehmungen an der petechialen. Form in ihren Anfängen, welche bei strengster Spitalordnung unter der fast stiundlichen 0 bsicht und Verbandpflege meines Medicinalassistenten Dr. König erhoben, mehreren ärztlichen auswärtigen Gästen, Dr. Schma uss aus Germersheim, Dr. Jakob aus Kaiserslautern klinisch vorgezeigt wurden, treten die analogen Heilerfolge an der confluirenden Form und aus den Gefahren heftiger Fiebergrade und symptomatischer Zufälle mehr in den Hintergrund. Diese gewinnen ihre grosse Bedeutung weniger durch die Macht der Zahlen, gegen welche sich mit glïcklichen Zufälligkeiten u. s. w. leicht Einrede machen lässt, als durch eine gewisse Identität der Sublimatwirkung in diesen scheinbar von dem hämorrhagischen Charakter so ganz verschiedenen Artungen der Blattern zum Zeichen der wurzelhaften Verbindung in der ganzen Familie.

Doch ich will vorerst die statistischen. Zahlen zur Vergleichung der Gewinnste und Verluste zwiscben den ärztlichen Erfahrungen der ganzen bayerischen Pfalz und denen des städtischen Hospitales in Speyer unter meiner Leitung sprechen lassen. Die Zusammenstellung bat das Gute, dass die Materialien derselben Epidemie, derselben Provinz ohne grosse Städte mit den ähnlichsten klimatischen Verhältnissen, derselben Bevölkerung von 630,000 Seelen, denselben Civilstandsregistern und einer Aufnahme von amtlicher Correctheit zur Vorlage an unser Ministerium entstammen.

Die summarische Liste läuft von Anfang Januar bis Ende Juni d. J. und lautet:

Erkrankungen.

$\begin{array}{cccc}\text { Vom Civil } & \text { Vom Militair } & \begin{array}{c}\text { Privat } \\ \text { behandelt }\end{array} & \begin{array}{c}\text { Spitälisch } \\ \text { behandelt }\end{array} \\ 5,057 & 151 & 4539 & 669\end{array}$

Todesfälle.

Civil Militair $\begin{gathered}\text { petechial u. } \\ \text { hămorrhg. }\end{gathered}$ confluir. $\begin{gathered}\text { Fieberhöhe, } \\ \text { access. Sympt. }\end{gathered}$

$\begin{array}{lllll}625 & 8 & 161 & 285 & 156\end{array}$

Sterblichskeitsprocent 12,15 . .

Von den 161 hämorrhag. Erkrankten wird ausserhalb der Stadt Speyer nur ein Einziger vom Bezirksarzt Blieskastel als genesen angeführt. Die expresse amtliche Nachfrage nach dem Verhältniss der aus confluirenden Blattern Genesenen zu den Gestorbenen stellt sich beiläufig auf $\frac{5}{4}$ zu 1 ; jedoch ist diese Erhebung sehr lücken- 
haft und leidet an dem Fehler willkürlicher Schätzungen, indem einige Bezirksärzte alle oder fast alle Erkrankten als genesen, und mehrere unserer tüchtigsten und erfahrensten alle als dem Tode verfallen angeben. Keinesfalls stellt sich aber das Genesungsverbältniss aus den amtlichen Angaben höher, als das oben angegebene.

Meine spitälische Liste läuft von Mitte Mai 1869 bis Ende Juli 1871 mit etwas mehr als 100 Kranken vom Civil. Vier Fünftheile und namentlich die petechialen Formen sämmtlich gehören diesem Jahre an.

\section{Erkrankungen. \\ Civil darunter petechiale confluirende \\ 100 in runder Zahl \\ 17 \\ 17}

Unter den confluirenden sind 8 doppelt gezählte, indem sie schon unter den petechialen stehen, weil sie aus diesem anfänglichen Charakter später in Confluenz meistens der extremsten Art übergingen. Bezüglich des Behandlungserfolges hat die Doppelzählung Recht, weil die Kranken unter der Fortsetzung derselben Methode die beiden Chancen glücklich durchgemacht haben.

$$
\begin{array}{ccc}
\multicolumn{3}{c}{\text { Spitälische Todesfälle. }} \\
\text { Petechial. } & \text { Confluirend. } & \begin{array}{c}
\text { Fieberböhe oder } \\
\text { sympt. Zufälle. }
\end{array} \\
3 & 4 & 0
\end{array}
$$

Das allge meine Sterblichkeitsprocent ergäbe hier 7; es hat aber keinen Werth, weil ein grosses Missverhältniss in der Zabl unserer graveren Spitalformen mit den auswärtigen, 100 zum Rechnungsfusse genommen, besteht. Dasselbe zeigte sich in den verschiedenen Monaten unserer Kantone, wo öfters wegen der baufenweise leichten Fälle auf $24-30$ kein Todter, bald wieder auf 10 Neuerkrankungen 3-4 Todesfälle kamen. Instructiv wird ein Commentar zu den Einzelverlusten, von welchen ich 1 in dem petechialen, 1 im confluirenden Stadium mit hoher Wahrscheinlichkeit Missgriffen meiner damals noch geringeren Uebung in Anwendung des Mittels zuschreiben darf.

Die 3 mit ungetilgtem petechialen Charakter Verstorbenen trugen zugleich alle Anzeichen einer späteren Confluenz. Der eine Fall wurde am 6. Tage nach dem ersten Ausbruche von Pelechien mit einem blauschwarz-russigen Aussehen ganzer Hautstrecken in das Spital rom Lande hereingebracht, erhielt sich noch 6 Tage lang 
leidlich in Ausbildung der Confluenz unter potenzirter Sublimatbehandlung, bis Blutungen und Delirien ein Ende machten. Der zwejte betrifft die oben geschilderte Frau, der dritte, wahrscheinlich schon mehr als 48 Stunden petechial, war der zweite dieser spitälischen Formen, woran ich mich als Anfänger noch etwas zu blöde in der Gabe vergebens versuchte. Doch điese Fälle mit eingerechnet, deren Kategorie ich bereits Eingangs eximirte, stellt sich mein Verlust auf 3 von 17 oder beiläufig wie $1 \mathrm{zu} 5 \mathrm{dar}$, in der übrigen Pfalz und dies nicht mit voller Sicherheit bezüglich des Ausnahmsfalles wie $1: 160$, d. h. 1 Genesener zu 160 Gestorbenen.

Unter den 4 Verlusten aus Confluenz zählen 2 ungeimpfte Kinder von 5 und 3 Jahren, wovon das ältere anfänglich petechial auf das glücklichste und heiterste ein wahrhaft scheussliches Eiterungsstadium auf der äusseren Haut bereits hinter sich hatte, unversehens von Noma ergriffen, bei der Section ausserdem zerstörende Geschwüre im Kehlkopfe zeigte, das andere $z u$ früh die Sublimatmaske über das Gesicht erhielt und unter wachsartiger Anschwellung und Färbung des Gesichts mit Räcktritt der Blattern starb. Die dritte Kranke, anfangs petechial, eines der entstelitesten protrahirtesten Exemplare, welchem wörtlich die Haut von Händen und Füssen fiel, versprach alles Gute, als sich mit neu erwachendem Fieber jauchig consumirende Periostitis der Fibula mit Fortpflanzung in das Fussgelenk zum Anfange eines raschen Endes entwickelte. Der vierte Todesfall, ebenfalls anfänglich petechial, entwickelte sich stürmisch zu der raschesten Confluenz. Der entzündliche Halo um die Pusteln trat alsbald zurück, und leicht möchte in diesem präcipitirtem Falle eher zu viel als zu wenig Sublimat angewendet sein. Wie man sich diese nähere Erlänterung zurecht legen mag, das Sterblichkeitsprocent bleibt ein en orm güustiges für Confluenz mit 4 Leichen zu 13 Genesenen oder beiläufig 1 Todter auf 3 Genesene um das Dreifache günstiger als das übrige ärztliche der Pfalz, welches so ziemlich anderwärtigen Durchschnitten entspricht. Unter den Genesenen befinden sich aber zur Steigerung des Vortheils 3 Männer zwischen 60 und 70 Jahren, 2 Schwangere, von denen die eine ohne Blutung 4 Wochen zu früh ein schwächliches, aber gesundes Kind während des Abtrocknungsstadiums im Spitale, die andere eine reife, gesunde Frucht bald nacb ihrer Entlassung gebar. Auch die aus der Reihe der Petechialen verstorbene Frau 
abortirte im 5. Monate ohne Blutungen. Ich lege auf diese Geburtsfälle einen namhaften Werth, weil bekanntlich ihre. Blutungen so häufig und so gefürcbtet, weil die aprioristischen Erwartungen vom Sublimate bezüglich seiner Beförderung der Blutzersetzung damit so bitter getäuscht sind. Mein Assisterizarzt hat diese 3 Entbindungen eigenbändig gemacht und alle unsere Vorbereitungen auf die Gefabr von Blutungen an den 3 Schwangeren so überflüssig gefunden, als bei anderen natürlichen Geburten. Gleichwohl war die eine später petechial Verstorbene in einer ungewöhnlich energischen Sublimatbehandlung begriffen, die beiden anderen aber batten bereits eine mehrwöchentliche energische Sublimatbehandlung bestanden.

Von Nachkrankheiten, sei es von Krankheitsresten, sei es von dem durchschnittlich hohen Verbrauche des Giftmittels sahen wir bei den aus den beiden graven Formen, der petechialen und der Confluenz Genesenen Nichts, im Gegentheil, ein Wohlgefühl der Reconvalescenz, wie es vach solchen Consumtionsprozessen und zweischneidigen Eingriffen der Kunst mir selbst fabelhaft erschien.

Ein Novum für die pathologische Doctrin des ganzen Blatternprozesses bleibt die Herausbildung der confluirenden aus der anfänglich petechialen Complication, deren glücklicher Verlauf bis zum Ende von den bisherigen Erfahrungen wegen des voreiligen Todes aus hämorrhagischen Zufällen nicht erschaut werden konnte. Dies gibt einen neuen Fingerzeig auf die organische Nothwendigkeit einer normalen und vollwichtigen Ausstossung der Pusteln und ihres bald mehr bald weniger typischen Verlaufes auf der äusseren Haut, worauf wir noch mehrmal zurückkommen werden.

In der summarischen Blatternliste von Confluenten wurde ohne Zweifel die Todtenzahl und die Ueberfluthung der Haut im Stadium der Reife geschätzt, und die Rubrik von Todesfällen aus Fieberhöhe und symptomatischen Zufällen apart gehalten, Auch mir ist öfters in den discreten Blattern, ganz absehend von den mancherlei Kreuzwegen, welchen die beiden oben berührten Formen, namentlich die confluirenden begingen, das beunruhigendste Zubehör der letzteren Rubrik vorgekommen, welchem jch mit Nichts als mit dem Sublimate meist nur für einige Tage entgegentrat. Die spilälische Liste bekräftigt den Erfolg mit Zero im Verluste, wo wir parallel zu der pfälzischen Statistik 3 Todte hätten zählen sollen. Es ist also gleich- 
gültig, ob die von den übrigen pfälzer Aerzten die Stadien vor der förmlichen Confluenz zu den Verlusten aus Fieber gezählt wurden, oder blos die stürmischeren Fieberzufälle der discreten, denn ich habe keinen Verlust weder aus der einen noch aus der anderen Reihe, welcher dem Fieber an sich angerechnet werden könnte.

Längere Zeit übertraf nach wenigen adäquaten Aenderungen in dem Verbrauche des Mittels die Gunst der Erfolge in petechialen Formen, und selbst in extremen Fällen der Confluenz dergestalt meine Erwartungen, dass ich mich fast zu dem Wahne einer absoluten Siegeskraft in dem Mittel verführen liess, jenseits des Römerspruchs: „est modus in rebus, sunt certi denique fines." Dieser Stein des Anstosses wird aber keiner menschlichen Rathund Handlungsweise vorenthalten und ich habe mich daher mit einer relativen zu bescheiden, welche freilich mir im Gegenhalte zu der bisherigen Statistik Unglaubliches leistete. Denn in Summa unserer confluireuden und petechialen entfallen 7 Todte auf $27 \mathrm{Ge}-$ nesene, also $1: 3$, ein Zablenverhältniss, welches fü klinische und statistische Kenner keines weiteren Wortes bedarf. Den petechialen Zahlen mit dem Einwande „post hoc, non propter hoc" fraglich zu begegnen, wäre lächerlich, das Mittel trägt die Schuld nicht, wenn das "initiis obsta " einmal unwiderbringlich versäumt ist. Die Zahlen in der confluirenden Form haben nicht allein den weiten statistischen Vorsprung für sich, sondern nebst der Wahrscheinlichkeit und der logischen Continuität im ganzen Krankheitsprozesse einen ungleich festeren Boden in früheren Erfahrungen auf dem pyämischen Gebiete. Gleichwobl macht ihre Unansehnlichkeit keineswegs den Anspruch, der fundamentale Stützpunkt dieses heroischen Mittels in Blattern zu sein, welcher mit seinen Folgen für die pathologisebe Doctrin auf dem petechialen Felde gar nicht zu bestreiten ist.

Empirische Manipulationsweise, Zufäle und Cautelen in der Anwendung.

Physiologische wie therapeutische Versuche müssen einseitig sein, wenn sie fruchtbar sein sollen. Dieser Satz wurde bier strengstens durchgeführt; ausser Säuren für den heftigen Durst und mit Ausnabme einiger ziemlich seltenen Zufälle, wovon später, kam kein einziges anderes Arzneimittel in den an sich schweren Formen 
aller Art zum Mit- oder Nebengebrauch. Die discreten Blattern liess man ohne Medicamente verlaufen, und nur bei fieberhaften oder sonst symptomatischen Bedenklichkeiten den Sublimat, und nichls als den Sublimat, walten. Im abermaligen diametralen Gegensatze zu den Schulmethoden war selbst in den petechialen Formen, mochten sie mit hohen oder niederen Fiebergraden einhergehen, die Entziehung von Nahrung oder diätetischen Reizmitteln bis auf schwache Fleischsuppen strenge Regel, ebenso in den confluirenden bis zum Eintrocknungsstadium. Nur etwas Obst oder Kaffee wurde nach Umständen gestattet.

Was die Dosis des Sublimates zu den Einwickelungen betrifft, so bediente ich mich einer Lösung von zweierlei Stärke, die eine mit $25 \mathrm{Gran}$, die andere mit $50 \mathrm{Gran}$ auf $18 \mathrm{Unz}$. destillirtes Wasser und 1 Unze Weingeist. Die schwächere war die anfänglich mebr griff weise gefundene, und that Monate lang ihre Dienste ohne irgend ein Misslingen, selbst an dem ersten unserer petechialen Fälle, welcher in den letzlen Tagen des Jabres 1870 spitälisch zuging. Weil die schwäcbere Lösung aber an einer Mitarbeiterin versagte, welche gleichzeilig von nicht desinficirter militärischer Blatternwäsche angesteckt war, aber wenige Tage nach der ersten eintrat, wo jene schon vom petech. Accidens genesen war, wurde später die stärkere erst ausschliesslich für alle petechialen Marken, und bald auch transitorisch in dringlichen Besorgnissen an den confluirenden eingeführt. Mit diesen Lösungen wurden rein gewaschene Leinwandlappen einigemal binnen 24 Stunden getränkt, gross genug, um nach Wahl und abwechslungsweise Unter-Oberschenkel, Obér-Vorderam, Brust, Bauch oder Hals in doppelten Blättern einschlagen und unter einer Decke von Wachspapier zur Haft und Verhütung äusserer Verdunstung umscbnüren zu können. Begreiflich, dass die petechialen Stellen die Vorhand batten, in den Achselhöhlen, in den Schenkelweichen mit einem getränkten Charpiebausche, im Gesicht mit einer Leinwandmaske besonders bedeckt, weil man zunächst auf die rein örtliche Einwirkung rechnete.

Der Verbrauch der starken Lösung binnen 24 Stunden schwankte bei Petechien $\mathrm{z}$ wischen einer starken $\frac{1}{2}$ und $\frac{3}{4}$ Flasche. Erst in der neuesten Zeit glaubte jch, bis $1 \frac{1}{2}$ Flaschen binnen 24 Stunden steigen zu dürfen oder vielmehr zu müssen bei einigen der oben erwähnten ganz exorbitanten oder veralteten Fälle, aber 
ohne Erfolg. Ich babe diesen, wo er überhaupt eintrat, mit Anwendung der stärkeren Lösung niemals länger als 3 Tage ausbleiben sehen, d. h. bis zum Verschwinden oder Verblassen der petechialen Flecke oder der einmal vorgekommenen Blutbeule. Manchmal blieb noch ein elwas livides Ausseben in den Umgrenzungen der sich im Uebrigen rasch zum normalen Stande eutwickelnden Pusteln zurück, wo ich dann nach der schwächeren Lösung griff. Ich möchte also nicht rathen, ohrie besondere Noth jenes obige Glücksmaass zu überschreitev. Die schwächere Lösung zu 25 Gran macht das gewöhnliche Hilfsmittel bei überfrequenten oder den Uebergang in Confluenz versprechenden Exanthemen und bei allen höheren Fiebergraden oder sonst bedenklichen inveren Symptomengruppen während der exanthematischen Reife aus. Es wurde mit Abwechslung der Hautstellen öfters mehrere Wochen die ganze Eiterungsperiode der confluirenden hindurch fortgesetzt, nach Umständen mit dem Verbrauche von $\frac{1}{2}$ bis zu $1 \frac{1}{4}$ Flaschen in 24 Stunden. Ich betone aber, dass jch auf Grund Sydenham'scher Indicien, mit Ausnahme des petechialen Zeitraumes, niemals bei confluirenden Blattern das Gesicht in das Bereich der Umschläge zog, bevor die Pusteln dort in voller Eiterung standen, weil jch bei einem ungeimpften dreijährigen Kinde die freie Entwickelung des dort überbäuften Exanthems gehemmt zu haben glaube, und dasselbe mit einer wachsartigen Anschwellung des Gesichts in wenigen Tagen verenden sab. Wo ich mich während des Ausbruchsstadiums durch bedenkliche Zufälle zum Gebrauche der Einwickelungen gedrängt sah, wählte ich vorzugsweise die Extremitäten, oder bei Gehirnaffectionen namentlich zugleich den Hals, ohne an diesen Stellen einen irgend hemmenden Einfluss auf die normale Weiterentwickelung der Pusteln beobachtet zu haben. Ich setze hinzu, dass ich von Anfang an richts weniger beabsichtigte, als die Entwickelung der Pusteln auf der äusseren Haut zu beschränken oder zu hemmen, wodurch anderwärtige Gebrauchsarten desselben Mittels, wie ich glaube, theoretisch und practisch fälschlich motivirt wurden.

Der durchschnittliche Verbrauch von Flaschen schwächerer Lösung, da ja mit der stärkeren immer nach wenigen Tagen bei guten Aussichten abgebrochen wurde, beläuft sich in den graveren durch Confluenz langwierigen Fällen auf einen Inhalt, welcher von 
$170-230 \mathrm{Grm}$. in toto bei mehrwöchentlicher Nothdurft schwankt. Es wurde damit 1 oder einige Tage ausgesetzt, wenn nichts beunruhigte, oder im täglichen Verbrauche ab und zugethan, je nach dem Stande der Allgemeinerscheinungen. Die schwer erkrankten 3 Kinder ertrugen ein Drittel, ja bis zur Hälfte des für Erwacbsene adoptirten Durchschnittsmaasses ohne irgend einen diesem Quantum zuzuschreibenden Zwischenfall. Von Petechialen, welche nicht in Confluenz übergingen oder ausnahmsweise von anderen Symptomen später beunruhigend beimgesucht wurden, hat keines mehr als 90-100 Grm. im Ganzen verbraucht. Diejenigen, welehe wegen Bedenklichkeiten unter das Regime dieses Mittels bald in stärkerer, bald in schwächerer Lösung mehr in intercurrenter Weise gesetzt wurden, blieben innerhalb der Grenzen von 50-90 Grm. Temperaturgrade von über $31^{\circ} \mathrm{R}$. auch ohne Nebenzufälle machten gewöhnlich Appel zur Anwendung des Mittels. Der practische Tact des erfahrenen Einzelarztes muss hier am Krankenbette ergänzen, wo ihm meine Schilderungen nicht minutiös genug für die Nachahmung scheinen; diesen Grad von Selbsterlernen wüsste ich ihm mit den schülerhaftesten Auseinandersetzungen doch nicht zu ersparen.

Noch will ich einer schlechterdings unentbehrlichen Nebenanwendung des Sublimats in den bekanntlich oft so dringlich gefährlichen Blattern der Schlingwerkzeuge und der Umgegend des Larynx näher gedenken. Auch diphtheritische Belege habe ich in dieser Epidemie dort öfter gesehen. Glänzend wirken Gurgelwasser von einer stärkeren Sublimatlösung, d. h. von 8 bis $z u$ 15 Gran auf 8-9 Unzen Wasser für 24 Stunden, sie wirken fast unfeblbar binnen $30-60$ Stunden durch deutliches Abortiren der Pusteln. Bei diesem diphtheritischen Belege that selbst der vorsichtige dünne Ueberstrich mit Liniment: Plenk: seine Dienste mit Verschorfung. Ich hebe diese Beobachtungen hier um so mehr hervor, als die Autorschaft nicht mir in erster Linie, sondern meinem alten Spitalfreunde Hrn. Prof. Skoda in Wien schon von dem vierten Decennium her gebührt, welcher bei seinen Versuchen auf den Augenhäuten diesen entschiedenen Erfolg zuerst bemerkte und so die Veranlassung zu späteren extensiveren Anwendungsarten in kosmetischer Absicht wurde.

Sprechen wir jetzt noch von den unangenehmen und späteren ZufäJlen, welche man vou solchen Gaben eines blutentmischenden 
Giftes in dieser acuten Krankheit der Schuldoctrin zufolge gewissermaassen als nothwendig voraussetzen sollte. Was die späteren Folgen des zum Theil enormen Verbrauches betrifft, so baben sie sich etwa nur durch die gliicklichste Reconvalescenz bekundet, mit um so grösserer Sicherheit auszusprechen, als ich einen guten Theil der Patienten aus hiesiger Stad, ja aus der grossen Spitalpfründe, viele Monate gar nicht ausser Augen oder Kundschaft verlor. Wem es beliebt, die obigen treu erzählten Nachkrankheiten des Noma und der consumirenden Periostitis dem Mittel anzurechnen, der hat wohl noch nicht viel von den haufenweisen Nachkrankheiten der confluirenden Blattern unter ganz anderer oder blos passiver Behandlung klinisch gesehen, und ich habe mich mit seinem ungefähren Urtheile nicht weiter zu befassen.

Die 2 leidigen Zufälle, welche ich dem Mittel zurechnen kann und muss, sind:

Salivationserscheinungen, bisweilen in ihrer Ursache schwer $2 u$ unterscheiden, weil sie öfter den natürlichen Verlauf der Blattern begleiten. Sie geboten bei den noch zweideutigen Anzeichen das sofortige Aussetzen des Mittels, waren gegen Erwarten sehr selten, und verliefen kurz und höchst gelind.

Ein weit bedenklicheres oder werigstens erschreckenderes Folgesymptom sind blutige Stuhlgänge erst mit schwach dysenterischen Spuren bald von reinem Blut, und keinesweges etwa der petechialen Form ausschliesslich oder vorzugsweise eigen, auch gerade nicht jenen, welche schon längere Zeit das Mittel in Abundanz verbrauchten. Unter den 40 mit Sublimat úberhaupt energisch Behandelten kamen sie etwa 9 mal vor, $3 \mathrm{mal}$ ausserdem im ultimo stadio der hämorrhagischen Blattern. Zum Glück ist dieses sofort zu unterdrückende Symptom lejcht und rasch zu beseitigen mit 1 oder $2 \mathrm{Ga}$ ben Tinct. opii croc. von 10-14 Tropfen und Klystieren mit ähnlicher Gabe. Ein nachtheiliger Einfluss auf den Gang der Hauptkrankheit hat sich von diesem Zwischenakte so wenig gezeigt, dass öfter nach einigen Tagen Pause das Mittel wegen anderer dringlicher Umstände ohne Wiederkehr der Fatalität wieder aufgenommen werden konnte.

Die bäufigen Diarrhöen dagegen, welche sich zu confluirenden Blattern unter jeder Medication häufig gesellen, habe ich aus System ruhig und ungestört ohne Aussetzen des Mittels verlauf́t iássen. 
Begreiflich wird bei dieser erst aus dem Ei geschlüpften singulären Behandlungsmethode in der Manipulationsweise und etwa in Combination mit anderen Mitteln noch gar Manches zu lernen, vielleicht anch abzuwerfen sein. lch gebe meine Erfabrungen nur mebr als tötale, Anderen überlassend, wie sie inre Fortbilùng weiter pflegen mögen. Die fötale Nacktheit ohne sonstige medicamentöse Einmischung, in welcher sie hier vorgeführt wurden, dient Anderen zurn Vortheil, die relativ kleine Werkstätte, in welcher sie erhoben wurden, dient dem Empfehler zum Nachtheile. Gar manche Zweifel, unter welchen ich Monate lang bangte, würde mir ein grösseres spitälisches Versuchstheater in wenigen Tagen oder Wochen gelöst haben, allein "nur ein Hundsfott", sagt ein gut altbayerisches Sprichwort, "gibt mehr, als er hat."

Meine practischen Motive und Directive zu und in der Sublimatbebandlung der Blattern.

Seit 30 Jahren, d. h. seit ich zu einer selbständigen spitälischen Thätigkeit gelangte, nehmen die Versuche mit Sublimat in acuten Krankheiten und in ihren mannichfachen Residuen nebst den Sandbädern höherer Temperaturgrade, welche ich zuerst auf das erfolgreichste in den ersten Stadien der rein en Bright'schen Krankheit in's Leben gerufen, das Centrum und grösste Interesse meiner practischen Heilbemühungen ein. Das erste öffentliche Anzeichen gab ich in meinen "physio-pathologiseben Studien" vom Jahre 1842 und bald darauf in einem der ersten Hefte der "Zeitschrift für rationelle Medicin" mit der kürzesten Notiz für Hospitalhrand und für ejne gewisse Form von Pueumonien. Wie sie sich allmählich nach den verschiedensten Richtungen und im Aufsteigen zu grösseren Gaben innerlich und äusserlich erweiterten und verbreiterten, weiss bruchstückweise die beträchlliche Zahl meiner successiven Assistenzärzte, und ist von mir gelegentlich in Vereinsversammlungen und ihren summariseben Comptes rendus laul geworden. Sie fanden im Ganzen sparsamen Glauben und noch sparsamere Nachahmung. Auch die sporadischen Blattern, welche ich seit langer Zeit nicht mehr in epidemischen Haufen zu behandeln Gelegenheit hatte, waren schon in den vierziger Jahren aus meinen älteren hypothetischen Scblüssen auf ihre diphtheritische Natur in- 
nerlichen Sublimatversuchen erfolglos zugefallen. Seit ich aber von seiner Wirkung in energischen Einreibungen immer Grösseres und Mächtigeres bemerkt hatte, sehnte ich mich wirklich nach einem neuen Tummelplatze mit den Blattern.

Der Weg, denselben in Umsehlägen mit kosmetischer Absicht beizubringen, war von der neuen Wiener Schule (H ebra) vorgezeichnet, jedenfalls schonungsvoller und weniger gewagt, als auf einmal grössere Mengen rascher urıd sicherer mitteist Einreibungen nach Wahl des Ortes in einer Dose von Scr. $\mathrm{j}$ bis zu Scr. ij auf 2 Drachmen Fett in 24 Stunden nach meiner neuen Handlungsweise bei hochkritischen Lagen in den Körper zu bringen. Aber so wenig diese, als ältere oder neuere Empfehlungen, die meist aus der Luft gegriffen, influirten im Geringsten auf mein eigenes Handanlegen, sobald sich spitälische Gelegenheit dazu finden wollte, denn das Miltel war mir in ähnlichen Lagen und Zwecken ein lange vertrautes.

Ich wnsste. seit vielen Jahren aus einer reichen Sammlung von Erfahrungen, erworben unter sorgenvoller Aufmerksamkeit bei Gewinnst und Verlust, auf das Positivste viererlei Eigenschaften des Sublimates bei energischer Anwendung:

1) seine relative Unịbertroffenheit in diphtheritischen Wundformen mit Gegenversuchen von ausschliesslich innerer und äusserer Anwendung erprobt. Eine nosogenische Verwandtschaft der Blattern und der Cholera zum Hospitalbrand hatte ich unter Anderem schon im Jahre 1833 in meiner Schrift: „Ueber das Verhältniss bei nervösem Fieber zur Cholera und Intermittens" anticipirt.

2) In gleichem Grade seine ungemeine Absorptionskraft auf Exsudate aller Art und aller Orten.

3) Seine unläugbar antipyämische Eigenschaft bis zu ciner gewissen Höhe des Uebels.

4) Seinen meist schon binnen 4-6 Tagen unverkennbaren Einfluss zur Tilgung oder ansehnlicheu Măssigung der Fiebersymptome, welche mit lokalen Depots oder allgemeiner Blutinfection aus obigen Grundursachen zusarnmenhingen.

Diesen längst in mir geprüften und gereiften Ueberzeugungen konnten weder Skeptik noch Skoptik das Geringste anhaben; diese hatten nur darin Recht, dass ich die Grenzdimensionen allzuweit vorschob, und mich damit auf Höhen von veralteten, halbzersetzten 
Exsudaten in tief herabgekommenen, soviel wie aufgegebenen Kranken wagte. Die Resorptionsstürme blieben nicht aus, aber sie wehten öfters das hinfällige Leben mit. Durch mehrere eclatante Niederlagen meines unvorsichtigen Ueberbietens schien nun ein für allemal der Stab über dieses Mittel gebrochen, welchem traditionelle Theorien längst ungünstig waren. Mir flössten diese verfrühten Bannflüche die Lehre zur künftigen Mässigung im Fortexperimentiren ein, nicht im Mindesten an dem wesentlichen Werthe des Sublimates irre geworden, aber auf schärferes Visiren der Grenzsteine bedacht, wo seine glückliche Wirksamkeit zur Beschleunigung des Verderbens dureh das von ihm nicht mehr Ueberwindliche umschlägt.

An mehreren grossen, veralteten pyämischen und ichorösen Heerden war vor 2 Jahren der Sublimat öffentlich gescheitert. Zahllose, aber begrenzte und frische Eiteransammlungen finden sich auch in den confluirenden Blattern, welche gleichfalls der Resorption und pyämisch-lhrombotischen Folgezufällen unterworfen sind, und zwar mit den glücklichsten Eigenschaften für eine antipyämische Probe. Denn hier ist das Eiterungsstadium und mit ihm die Eiterung typisch begrenzt, die Quelle nicht wie bei vielen anderen pyämischen Heerden in ihren Zuflüssen permanent, oder leicht wieder durch neue Anstösse von Iunen und Aussen neu zu eröffnen, der Abschluss von der atmosphärischen Luft oder anderen gasartigen Exhalationen zersetzender Natur wie z. B. im Bauche gegeben. Gleichwohl fehlt es schon dem äusseren Ansehen nach je nach Individuen und Stadien an den verschiedensten Nüancen der Eiterbeschaffenheit nicht. Hier oder nirgends konnte der Sublimat für gemässigte Erwartungen die offenste unverfälschteste Zeugschaft ablegen, ob er eine antipyämische Eigenschaft besitze, oder ob er nicht vielnehr mit seiner für das Normalblut giftigen Natur die von den aufgenommenen Eiterbestandtheilen eingeleitete Blutentmischung deutlich befördere? Denn diesen vernichtenden Vorwurf hatte man nicht etwa blos seinen Niederlagen, sondern für das ganze pyämische Bereich gemacht. Daher mein wahrer Heisshunger nach vergleichenden Maassen zwischen der Energie des Sublimates und anderen Curerfolgen in confluirenden Blattern. Jener Vorwurf aus falschen Voraussetzungen zerfällt in sein Nichts vor den zahlreichen glücklich und ohne Nachwehen zwischen 
den Klippen durchgeführten Musteremplacen, wochenlange geleitet von ersehreckenden Giftdosen. Man muss sich öfter die Glätte des Verlaufes bei Jung und Alt in den schwersten Fällen und die unglaublich rasche Wiedererholung unter dieser einfachen Behandlungsweise in Vergleiche zu anderen mitangesehen haben, um sich mit mir für eine positive Wirksamkeit, gleichsam für eine Desinfection der Eiterelemente in Pusteln und Blut zu entscheiden, was sich übrigens abermals und gleichzeitig in unserem grossen Barackenlazarette zu Speyer bei pyämischen Perioden der Verwundeten bestätigte. Grössere Sprünge zum Abfalle des Fiebers waren übrigens in der Confluenzperiode nicht bemerkbar, es verhielt sich vom Stadium der Bluithe an bei protrahirter Eiterung und oft noch bis zur Abtrocknung der Krusten in der Regel zwischen $31-32^{\circ} \mathrm{R}$, ohne den letzteren Grad länger als für einige Tage um mehrere Decimale zu überschreiten. Wie viel etwa durch das Mittel davon abgebrochen sein mochte, bleibt unbestimmt. Dagegen trat mit seltenen Ausnahmen eine Eigenthümlichkeit mit einer zu der höheren Temperatur ganz unverhältnissmässig gesteigerten Harnsecretion hervor, welche ich auch aus anderen Krankheitsprocessen als einen Begleiter des Sublimates kannte, und welcher sich als eine seiner glücklichsten Wirkungen erwies. Von dem relativ sicheren Posten auf dem Boden der confluirenden Blattern hatte es aber noch seine schweren Bedenken zu einem Salto mortale auf den petechialen.

Obwohl längere Zeit ein Lieblingsschüler Schönlein's aus seiner früheren Würzburger Periode und viele Jahre durch die grössten deutschen und pariser Spitäler gewandert, welcher der verschiedensten Aerzle Brauch sah und beobachtete, bin ich doch auf eigenen Füssen frühzeitig ein halber Autodidakt in dem therapeutischen Handeln, voll tiefer Skepsis an vielen seiner gefeierten Herrlichkeiten, geworden, trabe daher so Manches im Unterlassen und Handeln gewagt.' Nichts von diesen Anwandlungen hat mich aber jemals in grössere Spannung versetzt als die ersten Uebergänge mit dem Sublimate zu den petechialen Blattern, obgleich es Versuchen an allgemein aufgegebenen Zuständen galt. Ich spürte es erst an dem Beben in meiner Erwartung der Dinge, die da kommen sollten, mit wî̉ viel geheimen Fäden mich selbst noch im Innern jene hergebrachte, aller Welt eingefleischte Schablone von "Adynamie und scorbutischer Blutzersetzung“ in den petechia- 
len Blattern und manchen ähnlichen Zuständen anderer acuter Prozesse gefangen hielt. Denn ich war mehr gefasst auf eine scandalöse Verschlimmerung und rasche Steigerung der trostlosen Lage, als ich mir ein Gelingen zu versprechen getraute.

Es stand mir jedoch klar vor der Seele, dass ein Gelingen gleich sei dem plötzlichen Umsturz einer Menge von geheiligten pathologischen Anschauungen und therapeutischen Grundsätzen, welche auf jener Adynamie und scorbutischen Blutzersetzung fussen. Welcher besonderen Art die Blutveränderung auch in den petechialen Blattern sein mochte, sie konnte unmöglich der des gewöhnlichen Scorbuts gleichen, wo der Sublimat nicht säumen würde, ein Unheil anzurichten. Die Petechien der Blattern stehen aber keineswegs allein in der acuten Krankheitsreihe, sie reiben sich vielen Gliedern derselben als ein schlimmes Symptom z. B. den Typhen, gewissen Formen von Diphtherie, und der Pyämie häufig an. Half der Sublimat dort, so musste daraus erschlossen werden, dass diese Arten von Blutzersetzung etwas Ejgenthümliches, vom gewöhnlichen Scorbute Verschiedenes an sich tragen, was für sie den vorläufigen Collectivbegriff "falsche Blutzersetzung " rechtfertigt in dem Sinne, wie es nach der Nomenclatur des Brown'schen Systems eine "falsche Schwäche" gibt. Aus der symptomatischen Zusammengehörigkeit liess sich auf etwas Gemeinsames in ihrer geheimen, auf eine elementarische Verwandtschaft schliessen, und der entscheidende Sieg des Sublimates in dem Einen befürwortete kräftig genug, dass in inm eine gemeinsam corrigirende Tugend stecke, deren Grade begreiflich erst durch die Erfahrung festzustellen waren. Anhaltspunkte dazu fanden sich bereits in vielen meiner älteren Sublimatversuche, aber eine Sammelparole von solch durchdringendem Rufe hatte ihnen gefehlt. Wenn das sogenannte "schwächende und zersetzende“ Mittel auf einmal sich in den Petechien der Blattern, welche bisher unaufhaltsam die Katastrophe der allgemeinen Blutdissolution einleiteten, als ein wahres Tonicum erwies, mag man dies nun auf die Gefässwände oder auf die Cohäsion des Blutes oder auf beides beziehen, so war der Boden unter den grundsätzlichen Negationen zusammengebrochen und die grosse Lehre unbestreitbar, dass auf die Krankheitswelt nur mit der grössten Vorsicht und Umsicht übertragen werden darf, was experimentell oder abstract von der gesunden gilt. Physiologisch 
gesunde und feste Lehrsätze werden häufig bei ihrer "rationellen“ Uebertragung zum pathologischen Flitterstaat, sie erschöpfen übrigens häufig jene mystisch-heterogenen Elemente und Vorgänge nicht, welche sich der Krankheit ein- und aufpflanzen. Der Unterschied zwischen physiologischem und pathologischem Denken und Versuchen ist ein immanenter, nicht blos ein zeitlicher, oder wegen des $\mathrm{Zu}-$ rückbleibens des einen oder anderen Wissenszweiges zufälliger. Jenes steuert der mathematischeń Gesetzlichkeit in der Normale zu, und vermag sie stückweise zu erreichen, indem es sich bei seinen Experimenten auch nur einen sehr kleinen Theilinhalt aus dem unendlich Vielfachen der natürlichen oder selbstgeschaffenen Abnormen nach Belieben absondert und zergliedert. Bei all' dem bleibt es doch gewöhnlich mit all' seinem Ringen und Erringen hinter der Präcision und Solidität des streng physikalischen Wissens zurüek. Der pathologische Denker hat beim Handeln und beobachtenden Abstrahiren freilich auch den Normalzustand und die naturwissenschaftliche Methode im Kopfe, aber vor Augen den raschesten Lebensstrom, gepeitscht von dem Aufruhr aller körperlichen Leidenschaften zu Wellen mit zahilosen Kreuzungen und Durchschneidungen. Was zu seinen Füssen sich rubiger abschäumt und greifen lässt, ist meist nur ein Caput mortuum, arm oder ärmer an jenen Bewegungskräften, um deren gebeime Componenten und inneres Verhalten es dem böheren wissenschaftlichen Verlangen recht eigentlich zu thun gewesen wäre. Relativ zur Normale äussert sich die Krankheit, vornehmlich die acute, in einem mystisch-chaotischen Bewegungsspiele. Selbstverständlich treten keine nagelneue gesetzliche Lebensfactoren ein, aber eine Anzahl neuer, im stäten Wechsel begriffener Reagentien, Reactionen und Mischungsverhältnisse, für welche die Physiologie kein Maass und Gewicht und, ich möchte sagen, eben darum keinen Sinn und keine Zulänglichkeit hat. Jene räthselhafte Wesenheit, welche wir Einheit des Organismus nennen, besteht fort und zeugt gerade für die Wunder ihrer Zăhigkeit, wie sie sich bei den unaufhörlich forlgesetzten Angriffen auf sie von allen Ecken und Enden her dennoch so lange erhalten und so oft gleichsam nach ihrem Urbilde verjüngt und gereinigt daraus hervorgehen kann. Wenn es gelänge, das, was uns an diesen Knäueln noch alles mythisch-chaotiseh erscheint, in ächt historische Fäden aufzuwickeln, so würde nicht allein die Physiolo- 
gie, sondern auch die ethische Anthropologie um Unsägliches reicher und vollständiger. Darüber freilich ist kein Wort zu verlieren, dass ein soleher begreiflich sehr langsamer und unveränderlicher Fortschritt nur auf dem Wege naturwissenschaftlicher Methode erreicht werden kann. Dabei sollte aber ein anderes Requisit für den klinischen Pathologen nicht übersehen werden, welches der Geschichtsforscher von Jenem verlangt, welcher aus mythisch-poetischen Zeitaltern der Völker den factischen Bestand aus dem Nebelgewande der Sage möglischst zu sondern, und aus letzterem die Brücken zu den historischen Zeiten zu zimmern unternimmt - nehmlich mythisch-poetisches Mitgefühl zum divinatorischen Schwunge als nothwendigen Begleiter des streng-kritischen Verstandes zur klärenden Auslese. Es geht mit den Strebungen zur positiveren Erkenntniss in der Pathologie wie in der höheren Psychologie, welche neben einem Synthetiker von dem Geiste Spinoza's weder die Analyse einer warmen Gescbichte der Religionen, noch die der grossen Dichter entbehren kann. Von jedem ächt poetischen Hammerschlage sprübt auch ein Funke objectiver und philosophischer Wahrheit. Denn in vieler Beziehung verhalten sich naturwissenschaftliche Physiologie und höhere Pathologie in den Erschliessungsmedien des Geistes, in Werkzeugen und Procedur, wie in Sicherheit der Resultate zu einander incornmensurabel. Ewig wird letztere die unerschöpfliche Vorrathsund Räthselkammer für physiologische Strebungen bleiben, aber éwig mehr von taktvoller, instinctiver Empirik einerseits und halb mythischer Anschauung andererseits, als von strenger Wissenschaft an sich behalten. Aus diesem bleibenden Unterschiede zwischen ganz verschiedenen Aufgaben, wie sie auch einander zu durchdringen, zu fragen und auszubeuten streben, eine Rangstufe im Werthe fur die Menschbeit herleiten, die eine zu den empirischen Handwerkgriffen verweisen, die andere gegensätzlich schlechthin in das Sonnenlicht der Naturwissenschaft versetzen wollen, verräth den bornirten, pedantischen Doctrinär, welcher von all' diesen Dingen wohl läuten, aber nicht zusammenschlagen gehört hat. Zu Lande hat man gut sagen, wo und wie schnell man ankommt, auf der hohen See hat das aufgehört. Ist darum die Kunst des Seefahrens ein „Handwerk“ geblieben, wie empirisch sie sich auch oft zu behelfen noch fortfährt, und wie weit wären ohne sie die Naturwissenscbaften auf plattem Lande gekommen? 
Hierzu ein grosses historisches Beispiel, welches uns in medias res meiner nächsten technischen Aufgabe zurückfübren soll: Seit einer bestimmteren individuell weniger zusammenfliessenden Theilung der Arbeit zwischen Physiologie und Pathologie hat keine ärztliche Doctrin so tiefe Fusstapfen in jener, ja selbst in der Philosophie, bis heute zurückgelassen, wie die Lehre Brown's. Nicht als ob dieser eigentlich die Räthsel der Krankheiten en gros gelöst oder Conglomerate von Krankheitserscheinungen entdeckt bätte, welche früberen grossen Aerzten entgangen wären, allein er war der Glücklichste unter seinen Vorgängern, die bündigsten Worte für grosse Räthsel zu finden. Noch heute kann die Physiologie Worte solcher Art, wie "reizbare Schwäche", „directe und indirecte Asthenie" (uralt bezeichnet mit vires oppressae et subpressae) nicht missen, sie weiss ihre Wirklichkeit auf eigenen Versuchswegen nur mebr zu bekräftigen. Warum aber haben diese Schlagworte nach der ersten Beseeligungsepoche von einer relativ kurzen Dauer für die ärztliche Thätigkeit ihren Zauber eingebüsst? Finfach aus dem genügenden Grunde, dass gleich hinter dem Worte zum Räthsel die Räthsel selbst in lebendiger Gestalt mit einem combinirten Durcheinander, worin der Antheil eines jeden abermals und seine nächste Ursache dazu fraglich geblieben waren, vor den ernüchterten Blick des Arztes traten. Der Physiologe konnte sie sich einzeln im Ueberblicke ihrer Ursache schaffen, und ihre Einzelerscheinungen näher zergliedern, auf den Arzt stürzten sie meist allesammt in ungeordneten vermischten Gliedern als ein Naturobject zum Auseinanderklauben herein, und hätte ihm Letzteres gelingen mögen, so wurde Ursächliches, und wie ihm helfend beizukommen, damit kein bischen durchsichtiger. Thatsächlich ging der Streit ïber die Nervenfieber an, indem sich die Gegner zum Theil auf ihre entgegengesetzten Behandlungsweisen beriefen und sich dabei um directe oder indirecte Asthenie strilten.

Das Blut als Centrum der Krankheitsheerde und damit jeder humoralpathologische Nisus waren in den dunkelsten Hintergrund getreten; das Nervensystem als Angriffs- und Stützpunkt der Lehre vom Reiz und seiner consecutiven symptome hatte das ausschliesslich grosse Wort im Definiren und ärztlichen Eingreifen. Es thürmte sich ein wahrer Wall von "nervösen" Zuständen um gewisse Stadien, Arten oder Ausgänge del acuten Krankheiten ohne Ausnahme, 
welcher erst von der mehr localisirenden pathologischen Anatomie niedergelegt werden musste.

Wie viel auch von dieser Pseudonervösität seit 30-40 Jahren nach und nach abgeschüttelt wurde, namentlich seit man das Fieber mit ernsten Forschungen wieder in sein natürliches Recht einsetzte, bei der Behandlung der sogenannten Adynamie (ein anderes Wort für den alten Begriff Nervosität), welche sich mit acuten Prozessen früher oder später verbindet, sitzt uns die Erbschaft der Brown'sehen Theorie noch schwer im Nacken. Zu den unverwerflichsten Hauptzeugen der "Adynamie" im Grossen betrachtet gehören die Symptome von Blutzersetzung mit kleineren oder grösseren Blutergüssen unter der Haut, passiven Blutungen aus den Höhlen, ein vielen acuten Krankheiten gemeinsamer Grundzug von der schlimmsten Vorbedeutung. Reizmittel, diätetische und medicamentöse, in Verbindung mit tonisch adstringirenden verstehen sich dabei heute noch für jene, welche aus perfekter Skeptik nicht alles Handeln unterlassen, von selbst. Ihr allgemeines Fiasko in den petecbialen Blattern ist eine zugestandene Thatsache. Man müsste sich auf einen sehr kleinlichen Standpunkt botanischer Absonderung begehen, um nicht mit mir anzuerkennen, dass jenem rothen Blut-. faden eine gemeinsame, wenn auch mannichfach modificirte Ursache zum tiefsten Grunde liege, dass also ein Mittel, welches ihn in den ersten Einschlägen zu durchschneiden vermag, ausschliesslich auf den den Blattern eigenthümlichen angewiesen sei. Mit Phrasen aber, wie "Similia similibus curantur" befassen wir uns nicht. Ohne Zweifel hat also der schlagende practische Erfolg einen grossen Fortschritt in der summarischen Differentialdiagnose von inneren Blutzuständen mit sich gebracht, indem er, freilich ohne nähere chemische Bestimmung eine Scheidung zwischen zwei äusserlich identischen Erscheinungen aufdrängt, und einstweilen in negativer Weise eine prätendirte Klarheit beschämt.

Das Mittel verwischt also unter strenger Diät ohne andere medicamentöse "Reize“ oder „Kräftigung" einen der allgemeinen Charakterzüge acut ,adynamischer" Zustände, und löst, was nicht minder merkwürdig ist, mittelbar das Reifen des Pustelexanthems mit normalen Stadien aus. Es unterdrückte also nicht den typischen Prozess des Exanthems, sondern nur seine Ausartung. Wenn überhaupt mit dem Worte "adynamisch" etwas tieferes, als eine allge- 
mein verständliche Schablone gegeben wäre, so könnte dem Mittel der entsprechende Name eines dynamischen oder tonisch-reizenden erster Grösse schlechterdings nicht länger streitig gemacht werden. Jedoch sei dies nur in polemischer Redeweise für die doctrinären Gegner des Sublimates, welche an dergleichen traditionellen Begriffen wie Pech kleben und sich Wunder was darauf zu Gute thun, gesagt, als Erklärung, selbst nur als eine andeutungsweise, wäre sie mir zu arm.

A priori schon würde die Vermuthung guten Grund haben, dass ein Mittel von solch heilsamer Energie gegen einen der schlimmsten Ausläufer des adynamischen Haushaltes auf dessen ganze innere Wirthschaft nicht ohne erschütternden Einfluss sein könne, mit anderen Worten dass es nach weiterer Wahlverwandtschaft eine belangreiche Metamorphose im Blute selbst bewerkstelligen müsse; a posteriori lehnt sich der Erfolg in der hämorrhagischen Richtung correlativ an den zuerst erwähnten in der pyämischen Linie der confluirenden Blattern an, welche ein zweites Glied in der Kette der "adynamischen" Wesenbeiten ausmacht, allerdings hier sehr beschnitten in souveräner Gewalt, aber immerhin von eminenter Wohlthätigkeit. Die mir aus älteren Versuchen reichlich zu Gebote stehende Wirksamkeit in ähnlichen Constellationen kann füglich hier bei Seite bleiben; es sieht sich schärfer und besser auf festern Standpunkte bei einem begrenzten Horizonte.

Vortrefflich aber, dass das Heilmittel eines der in seinen Eigenschaften am besten gekannten corrosiven Gifte ist, so grosse Verwirrung es auch einstweilen im Schulconcepte anrichten mag. Wäre es unbekannter, unschuldiger Natur, oder eines jener räthselhaften Gifte mit Ausstrablung nach bestimmten Nervenprovinzen, so geheimnissvoll im Nervenbegange wie Strychnin, Curare etc., dann hätte die Theorie wenig oder nichts davon zu erwarten. Möchten die Erfolge auch ungleich weniger zu wünschen übrig lassen, als die des Sublimates, die Vermittelungsvorgänge zwischen Heilmittel und Krankhaftem blieben wo möglich noch mehr verhüllt, ohne Verheissung, früher oder später Blicke durch einen Spalt werfen zu können, indem das Dunkel des Mittels zu dem Dunkel des Uebels hinzuträte.

Ein Geheimmittel dieses Schlages selbst von unfehlbarer Heilsamkeit; gerecht für jeden Bader in der Anwendung, etwa ganz so 
sanft und indifferent geartet, wie ein gemüthlicher Spiessbürger oder ein rechtsstaatlicher Paragraphenritter sich ihre hausbackenen Wünsche und pauvren Ideale von dem medicinischen "Handwerk " zurechtlegen würden, enthielte keinen nährenden Kern für biologisches Sehnen und Denken, keinen Saamen, welcher der Theorie eine baldige Frucht verspräche. Je begrenzter die Glücksgabe z. B. auf eine Krankheits- oder eine Seucbenart wäre, desto magerer stellte sich voraussichtlich ein theoretischer Gewinn, während die Hoffnung natürlich mit Ausdehnung des Erfolges über eine weite Krankheitsfläche im geraden Verhältniss steigt.

Den Heilapparat in Blattern mit adynamischer Zubehör findet der Sublimat so viel wie ausschliesslich zur Zeit von China und Opium mit dem Anhange von reizenden und adstringirenden Dingen vertreten. Die Theorien üher Wirkungsweise und Formen dieser alten Erbstücke haben zwar öfters gewechselt, ihre Autorität im Ganzen ist dieselbe gleich einer unersetzlichen geblieben. Nun aber meldet sich ein stolzer Nebenbuhler. Vermittelung gibt es hier nicht, sondern einen Zweikampf, wer von den Gegnern das Feld zu räumen hat. Leichter wird dies mit dem Chinin gehen, woran ohnehin schon so mancher nüchterner Kliniker zweifelt, härter mit dem Opium, ohne Zweifel dem grössten Wundermittel der Medicin. Seine hochpoetische, mystische Weihe hat es freilich in neuester Zeit verloren, nachdem eine zeitliche Furcht vor ihm aus Reaction gegen den Brownianismus einer wahren Modesucht, es zu einem Gemeinplatze zu machen, gewichen ist. Als junger Arzt war es mein höchster Wunsch, es einst zur Sicherheit in seiner Anwendung bei kritischen Lagen zu bringen, und meine höchste Bewunderung von ärztlichen Thaten, wie Sydenham von seinem Eingreifen in den Blattern spricht. lch dachte nicht, eine Periode zu erleben, wo es des Besinnens wenig mehr braucht, weil die einstige Panacee in den Händen grosser Aerzte zu einem allgemeinen Cachelirzeug der Krankheit und der Patienten herabkam, "quia facit dormire" (morbum et tandem medicos). Ferne sei jedoch von mir die Anmassung, über die fernere Entbehrlichkeit des Opium in gewissen Zufällen der Blattern, namentlich der confluirenden und bei $\mathrm{Al}$ coholismus, absprechen $z 11$ wollen, um so mehr als es gegen meine Sublimatschäden seine alte Kraft bewies. Mir hätte seine Nebenanwendung die Reinheit der Sublimatversuche getrübt, und 
mein Gegeneifer galt nur der geläufigen Spielerei und Selbstberuhigung.

Was nun noch den deprimirenden Einfluss auf die Höhe des Fiebers und seine Begleitungszufälle betrifft, deren Gefabren in unserer pfälz. Verlustliste so zahlreich vertreten, und anderwärtig schon wohlbekannt sind, lieferte die confluirende Form keinen neuen Beweis dafür, weil wegen der gar nicht oder nur sehr kurze Zeit unterbrochenen Fortdauer der Medication nicht zu entscheiden war, was ohne sie geschehen wäre. Ueberhaupt ist diese Form, wo das Blut so lange in Verbindung mit unzähligen Eiterheerden steht, nicht die geeignete für zergliedernde Beobachtungen, es lassen sich summarisch einstweilen nur statistisch Vortheil und Nachtheil geltend machen. Es versteht sich einfach dabei, dass aus obigem Grunde von einem Abschueiden des secundären Fiebers so wenig die Rede sein kann, als das Mittel die in den Varioloiden mehr oder weniger cyclischen Stadien verkürzt oder verkürzen soll. In den discreten Blattern, welche noch nach dem Ausbruchsstadium in dieser Richtung Bedenken erregten, schwanden dieselben nach $3-4$ Tagen unter dieser Behandlung, wie man schon aus dem oben dafür angegebenen Pauschquantum des Verbrauchs ermessen kann. Ein einziger Fall unter diesen machte eine Fortsetzung von etwa 8 Tagen nöthig. Wollte man daher im Fieberpunkte klarer, von anderen örtlichen wenigstens den eitrigen Einmischungen ungetrübter sehen, so boten sich die Typhen mit ihrem langwierigen Verlaufe als der schicklichste Versuchsboden dar. Nachdem einmal die bedeutende Resorption des Sublimates auch in dieser Anwendungsweise feststand, betrat ich ihn in vorigen Herbste mit ziemlich schüchternen Anfängen unter glücklichen, aber nicht entscheidenden Erfolgen, mit kühner Entschlossenbeit in den Gaben, erst im Laufe dieses Jahres, gestätzt auf die obige Ideenfolge aus meinen Erfahrungen an den Petechien der Blattern.

\section{Zu dem Abdominaltyphus.}

Alle Welt, namentlich in der deutschen Medicin, kommt beute darin überein, dass in dem den welthistorischen vielgearteten Typhusprocess begleitenden Fieber der Schwerpunkt für seine theoretische und practische Würdigung liege, und dass dieses, vorah in dem Petechialtyphus, den veralteten Namen eines "essentiellen“ annähe- 
rungsweise am meisten verdiene. Die Periode liegt binter uns, wo die localen Concentrationen mit mannigfachen characteristischen Exsudaten in die Gewebe das Hauptaugenmerk absorbirten. Doch dürfte man bereits darin zu weit gehen, und in unlösbaren Widerspruch mit vielen früheren classisch beschriebenen Epidemieen und vielen heutigen gerathen, wenn die Höhe des Fiebers als Criterium für Rangordnung der Gefahren und Behandlung der Typhen den fast ausschliesslichen Ton angeben soll. Es würden offenbar die Gefahren zu gering angeschlagen, oder in Einseitigkeit übersehen, z. B. in dem weiten Capitel der sogenannten „Febres nervosae lentae" und vielen mehr acut verlaufenden Fällen, wo die mässigen Fiebersymptome so oft mit Hoffnungen täuschen. Wie oft treten nicht epidemisch und individuell bei mässigen Fiebergraden Intoxicationserscheinungen anderer Partieen des centralen Nervensystems oder sonstige locale Zufälle der schlimmsten Anzeichen weit in den Vordergrund! Diese Vorbemerkung soll der Werthachtung des Fieberprocesses nichts abtbun, sondern nur an das wichtige Recht anderer Exponenten des Typhus neben dem Fieber erinnern. Eine Rechenschaft, warum bei derselben Noxa in Blut und Zellen bald dieser bald jener den Vorsprung nimmt, können wir uns nicht geben.

Wohl in keiner andern Wissenschaft oder Technik gehen totale Umwandlungen in fundamentalen Begriffen, welche sogar etwas von Revolution an sich tragen, so geräuschlos vor sich als in der inneren Medicin. Theils darum, weil die Neuerer zu älteren Fahnen wieder bekehrt, aus sogenannter "Politik" ihren früheren Standpuukt ignoriren oder verleugnen, theils weil ihre Epigonen nicht mehr der Verführung jener mächtigen und neuen Motive ausgesetzt sind, von welchen ihre unmittelbaren Vorgänger und Vordenker hingerissen wurden. Dem Fieber als der grossartigsten und folgenreichsten Erscheinung kehrten die älteren Aerzte Jahrhunderte lang alle ihre Blicke im Denken und Handeln zu, welches sich sogar in de Haen, einem würdigen Vertreter der älteren Wiener Schule, bis zu dem objectiven Standpunkte der thermischen Messungen erschwungen hatte.

Die Franzosen, so ausserordentlich verdient um die Wiedererstehung der pathologischen Anatomie und um die Diagnose der Localisationen, glaubten einen Emancipationsact zu vollführen, wenn 
sie die traditionelle, ärztliche Servitut des Fiebers abschüttelten mit seiner Verweisung unter die von irgend welchem Localleiden abbängigen und davon bestimmten Symptome. Schönlein, für dessen diagnostischen Adlerblick und botanischen Sammelgeist z! einem "natürlichen Systeme" der Krankheiten diese Neuerung Wasser auf die Mühle war, eiferte mehrere Jahre für denselben Wahn, und Johannes Muller gedachte sich zu derselben Zeit rom physiologischen Standpunkte mit dem Fieber als einér blossen Reflexerscheinung abzufinden. Die älteren ärztlichen Zeitgenossen Deutschlands, theils übermannt von jenem glänzenden Kopfe, suchten ihren Mangel an localer Diagnostik, und darum manchen falschen Eifer gegen die pathologische Anatomie hinter den Verhan des Fiebers zu bergen, welchem sie aber mit ibren vergilbten Traditionen und neuen Hyperästhesieen keine frische Lebensseite abzugewinnen vermochten. Den Letzteren namentlich sehien das Blut eine viel zu ordinäre Hausmagd, um die nächste Causa movens des fieberhaften Zerwürfnisses in Frost und Hitze sein zu können, das Gangliensystem musste auch dafür einstehen, weil es am wohlfeilsten mit sich spielen liess.

Für mich wurde die Beobachtung der Cholera im Sommer 1831 der entscheidende Wendepunkt in meinen bisherigen Zweifeln. Jene zeitlich obherrschenden Autoritäten schreckten mich nicht $a b$, mich ihrem meiner Ueberzeugung nach nicht befruchtenden Strome öffentlich entgegenzustellen in meiner Schrift vom Jabre 1833: „Ueber das Verhältniss der nervösen Fieber zu Cholera und Intermittens." Sie arbeitete auf Wiedereinsetzung des Fiebers in sein natürliches Urrecht hin mit theilweise neuen vitalen Argumenten. Ein Wagestück waren damals meine Bebauptungen: das Fieber sei ein nothwendiger Ausdruck veränderter Blutmischung von der Art und Intensität, um auf den Respirationsprocess zu reagiren, sein Hitzestadium sogar nutzbringend zur Restitution des Blutes auf dem Wege der erhöhten Respiration resp. verstärkten Oxydation; sein Froststadium selbst habe einen succursalen kritischen Werth vermittelst des reichlicheren Blutandranges zu den secretorischen Organen des Unterleibs, im depuratorischen Sinne vorbereitend für das zweite Stadium. In dem letzteren Spiegel wurde speciell die Cholera betrachtet. Neben einer primären Fieberursache hatte das secundäre aus Resorption von örtlichen Affectionen, die Connexion 
und Mischung beider gar oft in den verschiedenen Stadien ein- und derselben Krankheit neben - und durcheinander gehend, ihre aphoristische Anerkennung gefunden. Diese grundsätzlichen Anschauungen, etwa mit Ausnahme eines Zweckdienlichen im Fieberfroste, erfreuen sich heute des allgemeinen Beifalls, man beeifert sich, sie mehr und näher auf dem Versuchswege zu bekräligen. Ausserhalb eines engeren Freundekreises wurde der Schrift vor 38 Jahren mehr deshalb, als wegen einiger anderer Excentricitäten, nur Ignorirung oder die Schmähung auf einen ,missrathenen Schüler Schönlein's“ zu Theil.

Die fortschreitende Anerkennung des Fiebers in seiner primären und secundären Bedeutung zu den verschiedenen Phasen im Gange des Abdominaltyphus hatte auch die namhaftesten Folgen für den Sinn in der Behandlung. Neuster Zejt will das Maass der Temperatur sogar ihr glïcklichster Leitstern werden. Daruiber unten noch einige kritische Worte, nachdem ich einen andern Punkt von nocb entscheidenderem Einfluss sachdienlich besprochen habe.

Es geschah nicht ohne Abstraction von dem Muster des Petechial- oder Kriegstyphus, welcher die lebhaftesten Eindrücke zurückgelassen hatte, dass auch alsbald unseren gewöbnlichen Typhen ein cyclischer Verlauf beigelegt wurde. Galt es aber, diese in ibren Stadien bis zum kritischen näher zu begränzen, etwa wie es Sydenham mit den noch nicht modificirten Blattern gelang, dann wollten freilich die ungemeinen Variationen in der Dauer des ganzen Verlaufs und in den Einzelstadien sich den Auslegungen nicht mehr recht fügen. Aus diesem Vordersatze, gestützt durch die klinischen Erfabrungen, mittelst neuerer wie älterer Behandlungsweisen dem Fortschreiten des Typhus kein Zoll Land mit directem Angriffe abgewinnen zu können, entwickelte sich die theoretische Zuversicht: "dass dieser cyclische Gang in seiner natürlichen Notbwendigkejt von keiner Kunst abgekürzt, oder durchbrochen ( "coupirt") werden könne" — daher das nach vielem Widerreden endlich allgemein durchgedrungene Losungswort: "zuwartende, mehr indifferente Behandlung, so lange nichts drängt, und im letzteren Falle symptomatische." Zur exspectativen wurden denn auch leichte Tonica, und eine bland nährende stickstoffreiche Diät gerechnet, in der beliebigen Präsumtion, die körperliche Abfuhr mittelst Fieber und Ausleerungen durch 
reichere Zufuhr möglichst ausgleichen zu wollen oder zu können. Als Ersatz für das Aufgeben eines directen Einflusses auf den krankhaften Cyclus bekannte man sich zu der tröstlichen Beschönigung, als ob man wenigstens die symptomatischen Gefahren sicherer am Zügel führe. Auf welchen schwankenden und zerbrechlichen Arzneifüssen diese Vertröstung bei diesen schwereren "Zufällen" steht und geht, hat wohl jeder erfahrene Kliniker bis zum Ekel erlebt. Was davon auf die bekannte Rechnung der "nervösen Adynamie" fiel, wurde mit dem alten Liede der tonischreizenden Scala in mannigfachen Variationen bald mehr bald weniger gläubig angesungen.

Symptomatisch aber im grossen Style verdient auch die neuste Methode in consequenter Anwendung kalter Bäder genannt zu werden, jedenfalls von einem ganz andern Belang, als die lästige Spielerei mit den Eisblasen. Sonderbarer Wechsel eben nicht zur Ehre für die Stätigkeit unserer Grundsätze! Als in den dreissiger Jabren einzelne Wasserheilanstalten anfingen, sich auf Versuche an fieberhaft-acuten Krankbeiten ejnzulassen, wurde auf sie von sämmtlichen gelehrten Aerzten ein Anathem wegen frivoler Vermessenheit geschleudert. Gleichwohl schwebte jenen, wenn auch in dunkleren Umrissen, kein anderer Grundzweck als der heute streng ärztliche vor. Namentlich aber im Gegensatze zu dem beruhigend-einschläfernden Larifari, welches mit seinen präsumtiv-unschädlichen Complimenten vor der Krankheit sich auch die Sporen im Typhus zu erschmeicheln gedachte, jst in dieser Procedúr der ärztliche Ernst, die Energie und die Einfachheit der Directive ein für allemal anzuerkennen, sie weiss, was sie will, und schon wegen dieser Eigenschaften darf man ihr für den Bestand ihrer Erfolge aufrichtig Glück wünschen. Allein absehend davon, dass sie wegen geschäftlicher Umständlichkeiten und moralischer Abschreckung schwerlich eine allgemeine Verbreitung erwarten darf, sagen schon die öfters plötzlich auftauchenden Pneumonieen in der Regel mit lethalem Ausgange aus, dass von ibr auch nur die Peripherie, nicht das Centrum der Scheibe getroffen wird. Sie wird aber immérhin einen historiscben Werth behaupten als curative Akme der wiedererkannten Fieberbedeutung.

Ich musste diese unparteiische aphoristische Entwickelungsgeschichte der Typhusdoctrinen, in so weit sie maassgebenden Ein- 
fluss auf die Behandlung geäussert haben, voranschicken, um mich auf Grund eines Extractes von äusserlicher Sublimatbehandlung in 4 aufeinander folgenden Fällen über zwei daraus resultirende folgenschwere Schismen gegen einige vermeintlich feststehende Lehrsätze näher erklären zu könrien.

Das erste Schisma nämlich behauptet: dass es allerdings möglich ist, den Verlauf unseres sogenannten Abdominaltyphus und zwar sowohl in den anfänglichen als weiter vorgerückten Stadien künstlich abzukürzen, d. h. sejner Gewaltsamkeit und Gefährlichkeit binnen eines Zeitraumes von 5-7 Tagen unter dem Verbrauche einer ziemlich gleichförmigen Gabe des Arznei- oder Giftmittels die Spitze za brechen mit einem kritischen Abschlusse. Dieser erste Abschluss war ein präliminärer, die ihn einleitenden oder bedingenden Krisen des ruhigsten Schlafs und profusen Hautdunstes brachen aber förmlich herein, und bildeten einen grellen staunenswerthen $\mathrm{Ab}$ schnitt. Um mich über den Ausdruck präliminär zu erklären, es glückte dem Sublimate, mit diesem kritischen Vorwerke von $36-$ 48stündiger Dauer das continuirliche Fieber in ein leichtes remittirendes fortan frei von aller und jeder nervösen Intoxicationserscheinung umzuwandeln, dessen Dauer unter sprungweisen, bald vorübergehenden Exacerbationen der Fieberhöhe, aber bei allgemeinem Erholungsgefühle, sich auf abermals $6-8$ Tage bemessen liess.

Das zweite Schisma, theilweise weniger heterodox, bezieht sich auf die nosologische Bedeutung der typhösen Darmentleerungen: Sie spielen nicht etwa eine blos accessorische oder passiv-symptomatische, sondern eine wesentliche depuratorische Hilfsrolle. Unverkennbar aber war deren Beförderung in Frequenz durch den Sublimat, noch weit angenscheinlicher und willkommener aber die Umwandlung ihrer Farbe nach wenigen Gebrauchstagen. Sie wurden öfters profus und häufig genug, um Schrecken einflössen zu können, man liess sie und das Mittel gewähren. Gerade aber bei den damit Besorgniss Erregenden stellten sich die perfectesten Abschlusskrisen ein, und gingen die Djarrhöen damit wie abgeschnitten mehrmals sogar in längere Stuhlverstopfung über. Durch die Menge oder Masse der Stuhlentleerungen sah man die des Harnes nie geschmälert, vielmehr eine der Sublimatwirkung eigenthümliche Zunahme.

Der conslante Farbenumtausch von der flockigen Erbsenbrübe zur gesättigt-biliösen verdient von nun an nicht mehri den gering- 
schätzenden Namen eines älteren ärztlichen Aberglaubens an solche "Zufälligkeiten", sondern mit Fug und Recht den ehrsamen einer glücklichen Abdominalkrise.

Zur Controle dieser Behauptungen folgt nun eine Tagesskitze über den Krankheitsveriauf in vier jugendlichen Personen nebst ihren anliegenden ${ }^{3}$ Fiebercurven aus den spitälischen Notizen:

1. Pfortz, Schmiedegeselle, 22 Jahre alt, am 31. Januar in's Spital getreten, seit dem 29. nach längerem Unwohlsein bettlägerig, hatte Tags zuvor ein Emeticum genommen. Puls 80 , Temp. $32^{\circ} \mathrm{R}$. Säuren.

Bis zum 2. Februar noch keine Delirien, aber unruhige Träume, täglich 4-6 erbsenbrïbige Diarrböen. Mittags der Anfang mit den Sublimatumschlägen aus einer Flasche mit 30 Gran gemacht.

3. Febr. Delirien, Roseola, Milz stark vergrössert, Meteorismus, 12 diarrh. Stuhlgänge der bisherigen Färbung.

4.-5. Febr. Die zweite Flasche verbraucht, 14 Stublgänge mehr gallig gefärbt, viel Urin, viel Durst, Kopfweh, Schwindel, nächtliche Delirien.

5.-6. Febr. Nur 2 dunkelfarbige Stuhlgänge, Meteorismus sinkt, Delirien unruhiger, trockne Zunge, viel Urin. Umschläge zum sparsameren Verbrauch auf den Hals reducirt.

6.-7. Febr. Wandeldelirien, kein Stuhlgang, kein Urin, der Katheter entleert $\frac{1}{2}$ Uringlas dunklen Harns.

Die 4. Flasche wird vollends verbraucht.

8. - 9. Febr. Die Delirien wäbren an bis Mitternacht - von da an plötzliches Versinken in den ruhigsten Schlaf, der mit halb offenen Augen aber völlig componirten Gesichtszügen, vollständiger Besinnungskraft auf heftiges Anrütteln, fast ununterbrochen unter heftigen Schweissen mit Miliarien an Bauch und Brust, vielem Urinlassen, bei feuchter Zunge - in den Nachtschlaf des 10. Februar übergebt. Die Curve zeigt den immensen Abfall des Fiebers vom 8 . auf den 9., welches sich dann mit einigen kleinen Schwankungen bis zum 16. ganz verliert. Der Stub!gang wenig und consistent, Durst wenig., Appetit bei feuchter Zunge schon am 11. Februar geäussert. Das Reconvalescenzstadium kounte man eigentlich schon vom 12. Februar ansetzen.

Subfimatverbrauch in Summa wäbrend 7 Tagen mit Einer Pause 4 Flaschen entbaltend 120 Gran.

2. Goerig, Commis, 23 Jahre alt, am 9. Juni in's Spital getreten, seit 6 Tagen nach beinahe ebenso langem tieferen Krankheitsgefübl mit allen Zeichen eines ungewöhnlich schweren Typhus bettlïgerig. Bauch stark meteoristisch; öftere Diarrhöen, Milz śehr vergrössert, Stumpfheit mit Delirien unterbrochen. Seit 6 Tagen tägliches mitunter heftiges Nasenbluten, handgrosser brandiger Decubitus mitgebracht. Mehrere Tage zuvor war draussen ein Emeticum genommen. - Einige Stunden nach dem Eintritt wurde mit dem Verbrauche einer Flasche à 30 Gr. für 24 Stunden in Umscblägen über den Bauch begonnen.

9. 10. Juni. Etwas Sebiaf, unterbrochen von leichten Delirien, Diarrhöen 11, 
ausserdem mehrere unwillkürliche, zweimal Nasenbluten, Urin sparsam und dunkel gefärbt. Die zweite Flasche in Angriff genommen.

10.--11. Juni. Delirien, Puls schwach, Muskelzittern, mässiger Fusten, Urin $1 \frac{1}{2}$ Schoppen, heftiger Durst, Meteorismus in Abnahme, mit den 8 bewussten Stühlen entleerte sich eine Masse von Gasen, Besinnungskraft am Tage getrübt, Sprache unsicher.

Die dritte Flasche um die Brust ord.

11. - 12. Juni. Nächtliche Delirien, 12 diarrh., biliös gefärbte Stuhlgänge, Gesicht componirter, Urin copiös, hell, Haut fängt an zu duften.

$\frac{1}{2}$ Flasche.

12.-13. Juni. Wegen Vorzeichen von Salivation wurden am gestrigen Abend noch die Umschläge entfernt, die nächtlichen Delirien bland, das Bewusstsein beì Tage ungetrübt, 3 biliöse consistentere Diarrhöen, Urin 4 Schoppen klar, strołgelb, Haut schwitzend, reichliche Miliaria am Bauche. Nachmittags am 13. Schüttelfrost von $1 \frac{1}{2}$ stündiger Daner mit nachfolgender Hitze von $32,5^{\circ} \mathrm{R}$. Die Brandplatten des Decubitus stossen sich anfänglich $a b$, darunter die gesundesten Granulationen. Beträchtliche Abnahme der Milzanschwellung.

13.-14. Juni, Enormer Abfall des Fiebers, Nachts ruhiger Schlaf, reichliche Schweisse, Urin röthlich $1 \frac{1}{4}$ Schoppen, 3 gelbbraune Diarrhöen, Durst mässig, Zunge feucht, aber belegt, Meteorismus ganz verschwunden, auch ausser den Stuhlgängen reichliche, tönende Flatus.

14.-15. Juni. Der ruhigste Schlaf auch stundenweise am Tage, Wohlgefühl bei grosser Müdigkeit, Urin wie gestern, Diarrböen desgleichen.

15.-20. Juni. 3-4 bräunliche Diarrhöen dauern fort, mässige Schweisse, Urin 2-3 Schoppen, Fiebergrade mit abendlicher Steigerung mässig, ohne das subjective Woblbefinden im Mindesten za stören.

21. Juni. Decubitus vollständig vernarbt, der erste, feste Stuhlgang, Appetit gut, Milz zum normalen Volumen zurïckgekehrt, Urin reichlich, so fort bis zum 26. mit Stublverstopfung, wo noch einmal hohe Fiebersteigerung mit trockener Zunge, Verlust des Appetits, dunkelrothem Urin eintrat, um sich am 27. nach provocirter Entleerung einer Masse knolligen Kothes zu verlieren. Von da ab rasche Kräftigung des Kranken, welcher am 8. Juli das Spital heiter und wobl verliess.

Sublimatverbrauch etwa 100 Gran binnen 4 Tagen.

3. Scharfenberger, Anna, 17 Jahre alt, 2 Tage betuägerig, 8 Tage unwoll vor dem Eintritt in's Spital am «1. Juli. Neben den gewöhnlichen Symptomen des Abdominaltyphus vorstechende Muskelzuckungen, Sehnenhüpfen, beständiges Umberwerfen obne Delirien. - Calomel 6 Gr.

21.-22. Juli. 3 breiige Stühle, Schwindel, Schlaflosigkeit, wenig dunkler Urin, Leib leicht meteoristisch, Zunge weiss belegt, feucbt. - Säuren.

22. - 23. Juli. 2 grünliche djarrhoische Stühle, wenig Urin, sonst dieselbe Lage. - Mit Sublimatumschlägen zu $\frac{1}{2}$ Flasche für 24 Stunden begonnen.

23. - 26. Juli. Status idem mit mehrmaligem Nasenbluten ohne Erleichterung.

Urinmenge nimmt $\mathrm{zu}$, am 24. kein Stuhlgang, am 25. zweimalige biliöse Diarrböen bei leichtem Meteorismus des Bauches. An jedem dieser Tage $\frac{3}{4}$ Flasche verbraucht. 
27.-28. Jułi. Vorzeichen von Salivation, Umschläge ausgesetzt. Muskelzucken verschwunden, zum erstenmal ruliger Schlaf während der ganzen Nacht, damit Kopfweh und Schwindel beseitigt; einige braun saturirte resistentere Entleerungen, Durst mässig, Zunge noch immer belegt, kein Appetit. Die Lysis des Fiebers zu einem mehr remittirenden tritt deutlich hervor.

29. - 31. Juli. Nochmals mit Umschlägen za $1 \frac{1}{4}$ Flaschen für 2 Tage begonnen, unter Fortdauer von einigen braungelben mebr diarrhoischen Stühlen, 2 und etwas mehr Schoppen saturirten wolkigen Urins täglich bei ruhigem Schlafe mässigem Durst, Appetitlosigkeit, Schwinden des Milztumor.

31. Juli. Abermals Spuren von Salivation. - Umschläge weggelassen.

So dauerte die Lage mit einer förmlichen Remittens ohne allen Einfluss auf das allgemeine Wohlbefinden unter einigen täglichen breiigen Stuhlentleerungen mit relativ sparsamen höher gefärbtem Urine bis zum 9. August fort, wo Puls und Temperatur auch in den Abendstunden sich der Normale enge năherten. Am 14. verliess die Kranke zum erstenmale das Bett in dem heitersten Gesundheitsgefühle.

Sublimatverbrauch 100 Gran während etwas mehr als 7 Tagen.

Sie war im Gegensatze zu den früheren nicht zu den stürmischen Darmausleerungen gelangt, und es ist ibr weit länger Appetitlosigkeit zurückgeblieben.

Allein Appetit oder nicht, sämmtliche wurden noch während der Lysis-Periode in derselben strengen Diät, wie während der typhösen Sturmzeit gehalten - gewöhnlicbe Fleischsuppen obne Brod zur Mablzeit, etwas Kaffee Morgens und Nachmittags, während der Lysis etwa durch 1 Ei oder gekochtes Obst vermehrt.

4. Blochmann, Backer, 30 Jahre alt, erst 2 Tage vor seinem Eintritt in's Spital am 11. Angust erkrankt, als ganz frischer Fall von besonderem Interesse fïr die Perioden von Krisis und Lysis. Kopfweb, Schwindel, taumelnder Gang, Haut trocken, Zunge dick belegt, feucht, Bauch mässig meteoristisch, Milzdämpfong erst im Beginnen; Abendtemperatur 31,9 bei -96 Puls.

12. Aug. Schlaf mit unruhigen Träumen, 1mal Diarrhoe, $1 \frac{1}{2}$ Schoppen tiefbraunen Urins (beiläufig gesagt, bei weitem die geringste tägliche Menge unter allen obigen Kranken, welche bei diesem bis zur Reconvalescenz constant blieb), Husten mit katarrhalischen Sputis, Morgens der Puls auffallend langsam, 72.

Bis zum 13. Mittags 1 Flasche à $30 \mathrm{Gr}$. zu verbrauchen.

13. Aug. Nachts varuhige Träume, 4 diarrhoische Stuhlentleerungen, Urin derselbe, Temperatur um 0,9 gefallen, Milzdämpfung reicht von der 7. Rippe bis za dem Randbogen $11 \mathrm{Cm}$. betragend; - eine weitere Flasche.

14. Aug. Unruhige Nacht, Zunge dick belegt, nicht trocken, 4 Stuligänge dunkelgelber Färbung, 1 $\frac{1}{4}$ Schoppen Urin derselben Farbe und Beschaffenbeit.

$\frac{3}{4}$ Flasche.

15. Aug. In der Nacht der erste rubige Schlaf. Morgens leichte Salivation, Aussetzen des Umschlags; Temperatursteigerung um $\mathbf{1}^{\circ} \mathrm{R}$, 4 dichtere, tief gallig gefärbte Stuhlgänge. Schwindel, Kopfweh mässiger, Milzdämpfung geht zurück. Urin derselbe, Durst mässig, Zunge belegt, feuebt.

17. Aug. Nach 2 guten Nächten bei dem nehmlichen Morgens erhöhten Fieberstande ist jede Spar von Schwindel und Kopfweh gewichen. Selbst bei Tage stellt 
sịch őfter rubiger Schlaf ein, Appetit regt sich, 2 biliöse Stublgänge. - Hant stellenweise duftend.

18.--19. Aug. Abfall der Morgentemperatur auf $30^{\circ}$ R.," Urin in dem bisherigen Maasse, Milzdämpfung beginnt an der VIII. Rippe, Meteorismus gänzlich ge. schwunden, Haut schwitzend, subjectives Gesundheitsgefühl bei porgeschrittener Abmagerung des Körpers. Eine leichte Salivation hatte sich bis beute erhalten.

Von nun an hören auch die abendlichen Temperatursteigerungen bei einem bis zu 64 berabfallenden Pulse auf, es tritt förmliche Stublverstopfung bei gutem Appetit ein and mit dem 20. die vollste, ungestörtéste Reconvalescenz, womit erst mehrere Tage lang eine massenhafte Menge Urins sich zu entleeren beginnt. Am 24. ausser Bett.

Der Verlauf verliert in diesem Falle seinen Doppelchärakter von Krisis und Lysis - im Grossen Ganzen genommen năhert er sich mebr der Lysis.

Glaubt man sich mit diesen naturgetreuen Schilderungen nicht plötzlich wieder mitten in die Brennfieber Griechenlands, wie sie Hippokrates mit ihren plötzlichen und regelmässigen Abfällen zur heilsamen Krise beschreibt, an welchen man so oft in der Gesichtsweite unserer. Krankheiten gezweifelt hat, zurückversetzl? Wolle man docb damit das stürmische Unterliegen oder den schleppenden Gang unserer Abdominaltyphen und der zwitterhaften, unbestimmter localisirten Formen, als Schleimfieber, als Pneumo-Cerebral-Typhen nominell untergebracht, unter jeder andern Behandlungsweise oder beim Ueberlassen an die Natur vergleichen. Was giebt es Ermtidenderes in-der Behandlung acuter Krankheiten als jenes Hangen und Bangen des Arztes unbestimmbare Wochen lang, wenn auch das Fahrwasser augenblicklich noch so sicher scheint, auf die vielerlei Zufälle, welche mit jeder Stunde eintreten können, und welche er meist nur mit den unzuverlässigsten Hülsmitteln abzuspeisen vermag! Ich kenne nichts in der ganzen Heilkunst-ernster acuter Krankheiten, was einem unmittelbaren Angriffe auf die eigentliche Krankheitswurzel dem Erfolge nach auch nur entfernt so ähnlich sieht. Sogar jener selten glückliche Griff des genialen Arztes Adalbert Mareus, des ersten Directors am Krankenhause zu Bamberg, in dem Kriegstyphus von 1813 nach Aderlässen coup sur coup; deren schlagende Wirkungen ich oft von seinem assistirenden Schüler (Dr. Funk d. ä.) mit Befremden habe rühmen hören, verhält sich dagegen, wie ein symptomatischer Behelf.

Vor dem gleichförmigen Zusammentrefien der für den glücklichen Erfolg gewichtjgen Momente, welche sich gleichsam in allen 4 Fällen copiren, würde sich jede Einrede von "Zufälligkeiten ", 
welche ihren genauen ursächlichen Zusammenhang mit dem Mittel bei Seite schaffen möchte, lächerlich machen. Sage man: „Wer steht uns für die regelmässige Wiederkehr eines solchen fabelhaften „Glücks" bei einer derartig kühnen, ausser aller bisberigen Berechnung liegenden Medication? Wer bürgt dafür; dass namentlich die stürmischen Diarrhöen nicht zu Blutungen oder andere Zufälle zu unheilvollem Collapsus in anderen Fällen zu anderen Zeiten entarten?“ Einwände dieser Art nehme ich mit Bescheidenbeit hin, mir woblbewusst, dass 4 noch so erstaunlich glückliche Erfolge so wenig, wie Eine Schwalbe-den Sommer, solchen in der Medicin versprechen. Nü die methodiseb-stereolype Ordnung, zu welcher sicb der Abdominaltyphus unter der Wucht dieser Medication mit raseber Entscheidung bequemt, und die seltsame Concordanz seiner Wirkung mit der sichtlichen in den petechialen Blattern, welche gleichfalls unter dem Schulzeichen von Blutzersetzung stehen, lasse man einstweilen in Ruhe vor erfahrenen, wabrheitsliebenden Männern, welche sich in einem langen Leben gleich mir vielfach in den typhösen Verwirrungen bewegt baben.

Von jeher gewohnt, das scheinbar Riskirteste bei innerem Drange dazu allemal auf meiue alleinige Verantwortlichkeit zu nehmen, und Andere damit nicht weiter zu behelligen, bezweckte ich auch mit dieser frappantesten aller Heilproben keineswegs eine Provocation zur Nachabmung, obschon ich für meinen Theil, bis mich etwa traurige Erfahrungen abschrecken, nie mehr einen andern bekannten Heilweg betreten oder privat conciliarisch rathen werde. Was auch die Folge für minder günstige Erlahrungen bringen mag, man hätte dennoch Ursache genug, dieser Behandlungsweise bleibend dankbar zu sein für die durch sie gewonnene klare Einsicht in die Bedingungen und Umstände nach ihrer Reihenfolge, unter welchen der Abdominaltyphus mit acuten Krisen zur unbedenklichen nachträglichen Lysis sich abschäumt. Diese sind Punkt für Punkt einer weiteren Epikrise werth, welche zugleich manche ältere Streitfrage zu entscheiden, und die doctrinäre Sublimatfurcht 'mit Negationen ihrer gratuiten Voraussetzungen zu beschämen geeignet ist.

1 Verhältniss der Diarrhöen zur Entscheidung des Typhus.

a) Quantität oder Frequenz.

In 3 Fällen sahen wir sie hier bald dem Sublimatgebrauche 
in sturmischer Ueberfrequenz, aber ohne Leib- oder tenesmusartige Schmerzen und blutige Beimengsel, folgen, Einmal mit der Lysis wie abgeschnitten, das übrigemal während der ganzen Lysis in mässigem und consistenterem Grade fortdauernd. Ich habe den Schrecken Anderer vor der Frequenz der Stühle schon längst nicht getheilt, weil ich in vielfacher früherer Beobachtıng der Handlungsweise Anderer, aus theoretischen Gründen auf das Stopfen bedacht zu sein, nichts Gutes gesehen. Meinen mehrjährigen Arbeitsgenossen in der damaligen an Besuchern verwaisten Leichenkammer des Wiener Krankenhauses aus der ersten Hälfte des dritten Jahrzehntes - Rokitansky und Skoda - werden sich des vielen leidenschaftlichen Streites erinnern, mit welchem ich auf dem Werthe der den typhösen Darm meist so reichlich and zäh üherkleidenden Schleimschichte bestand, für meine singuläre Anschauung von keiner geringeren Bedeutung in der krankhaften Arbeit; als die Veränderungen der Darmdrüsen selbst. Mich drückte es also damals schon, wo sich Alles um die letzteren zu drehen schien, gar nicht schwer, wenn sich öfters von denselben keine Spur oder nur Andeutungen fanden. Ich hatte diesen Diarrhöen wie den cholerischen schon in meiner Schrift von 1833 den Namen "vorbereitende Krisen" (begreiflich ohne Bürgschaft für das endliche Gelingen) gegensätzlich zu den "glückverkündenden" am Ende der Krankbeit gegeben, eine in der Natur der Dinge gegründete Unterscheidung, obwohl sie in praxi sehr wenig beherzigt wird.

b) Qualität, insbesondere die Färbung und iłr Umschlag von der flockig blassgelben in die eigentlich gallige.

Bei der mehr grünen Farbe, sogenannten Calomelstühlen, sind Täuschungen über die Herkunft der Farbe möglich, indem ich mich nach dem Vorgange Skoda's öfters überzeugt habe, dass jenes Mittel die Darmsecrete bisweilen ganz in derselben Weise verändert in Fällen, wo absolut der Zugang der Galle verschlossen war. Darauf fusste sich eine Zeit lang die Absicht und Ansicht, damit den Typhus "coupiren“ zu können. Von solchen Irrthümern befreit die rein biliöse Färbung, welcher alsbald auch eine grössere Consistenz der Stühle zu folgen pflegt. Dass diese hier vom Sublimate herbeigeführt wurde, ist kein Zweifel, wohl aber erhebt sich gar mancher darüber, dass chemisch betrachtet Calomel im Körper zu Sublimat werden müsse, und also gegen die Voraussetzung endlicher identi- 
scher Wirkung von Calomel und Sublimat. Doch das mögen andere dazu Berufene in's Reine bringen. Mir erscheint nur diese Veränderung der Stühle und resp. der Lebersecretion selbst, da in der Gallenblase der Typhusleichen der Inhalt meist wässrig blassgelb betroffen zu werden pflegt, von einer ungemeinen Tragweite zur günstigen Gestaltung der Krankheit. - Nach diesen neuesten Wabrnehmungen wird aber Nichts mehr mich von der Ansicht zurückbringen, dass in der Beschaffenheit der Gallensecretion und in ihrer Wechselbeziehung zur krankhaften Darmsecretion noch ein grosses Geheimniss mit scientifischen Mitteln zu entdecken sei, und dass der gesunde Instinct bei einer naiven Nalurbeobachtung die älteren Aerzte und Schulen seit den historischen Zeiten nicht betrogen hat, wenn sie in roher Weise einen gewissen Gegensatz zwischen "pituita“" und ,bil“" statuirten.

Was aber das Capitel der Darm- und Lebersecretionen in Allgemeinen betrifft und die heutige Mode, sub voce "Magen- und Darmeatarrh" die nach Ursachen und Anforderungen an die Behandlıng verschiedensten Leiden über Einen Leist zu schlagen, so ist damit Niemanden als der Mappe und dem Augenmaasse der Schüler gedient.

2) Relativ zur Heftigkeit des Fiebers und der Stublentleerungen abundanter Urin, ein regelmässigcr Begleiter der Sublimatwirkung, bei welchern mir allemal das Herz lacht, bei dessen Constanz ich weit weniger die Fieberhöhe oder andere Besorglichkeiten scheue. Erst zur Zeit der Glückskrisen und während der Lysis wurde er öfters sparsam und gesättigter. Zu sogenannten kritischen Sedimenten kam es nicht, oder nur sehr vorübergehend.

3) Nervenkrise des Schlafes, vom Petechialtyphus in Vorlesungen und Lehrbüchern so oft en bloc auf den Abdominaltyphus übertragen, wo sie aber doch nur in Bruchstücken zu erscheinen pflegt. In Wirklichkeit dürfte sie hier wohl noch nie wieder in so rascher Wandlung und continuirlichen Ausdehnung auf $30-36$ Stunden mit geringen Unterbrechungen beobachtet worden sein. Dieses Naturschauspiel, welches bier in seiner ganzen idealen Grösse und Wohlthätigkeit erschien, indem von seinem Eintritte an jede unruhige Agitation des Gehirus und Rückenmarks ein für Allemal weggezaubert war, war nicht die Ursache, sondern die Folge der Besserung und beginnenden Heilung. Die Ursache des Phänomens 
liegt in den so weit wieder bereinigten Zuständen des Blutes, ist unnachahmbar und unersetzlich von künstlich schlafbringenden oder betäubenden Mitteln. Diese simuliren dann nur die äusserliche Erscheinung mit einem Sopor, welcher von dem krankhaften kaum verschieden sein dürfte; wir wissen nicht einmal, ob trotz der $\mathbf{A b -}$ stumpfung des Bewusstseins der Conflict der krankhaften Blutelemente mit den nervösen vielleicht in einem noch schädlicheren Maasse fortảuert. Denn von Erholung lässt sich nach einem künstlichen Schlafe in derlei acuten Blutintoxicationen wahrlich nichts verspüren. Die Kranken fühlen sich beim Erwachen, wenn anders die Absicht erreicht wurde, meist noch aufgeregter und unheimlicher zum Danke für die ärzlliche Bescheerung. In unsern Fällen stellt sich der Schlaf nicht als ein künstlich unzeitliches Geschenk, nicht als ein kritisch-befreiender deus ex machina, sondern als der natürliche Bedürfnisszwang der von den krankhaften Reizen in reizbarer Schwäche halb erschöpften Nerverkkräfte dar, welche sich durch die Ruhe restauriren, und sich aus dem ihrer normalen Ernährung wieder adäquaten Blute sammeln wollen. Die Länge und Tiefe des Schlafes zeigt uns den Grad der Müdigkeit oder Erschöpfung um so deutlicher an, weil die dazu unerlässliche Veränderung in dem Gesammtblute so ausserordentlich rasch und vollständig vor sich gegangen war.

4) Einzelne Hautstellen, insbesondere des Gesichts, fühlten sich schon nach 3-4 Tagen der Behandlung duftend an, bis mit der Schlafzeit allgemeine Schweisse öfters profuse eintreten. Ich halte meine alte Ansicht aufrecht, dass die sogenannt kritischen Hautschweisse keinen capitalen Antheil an der Entfernung positiver Krankheitsstoffe nehmen. Sie beweisen mehr für die glückliche Lösung der krampfhaften Hautspannung, wodurch in glücklichem Gleichgewichte zu den anderen Secretionen dieses wichtige Organ eben auch wieder in diese seine Function treten kann. Gleich dem kritischen Schlafe hat die neu erwachte Thätigkeit der-Schweissdrüsen weit mehr den Werth eines Vorhoten, eines Anzeichens der restitutio in integrum, als den eines Mit- oder Nachhelfers.

5) Der deutlich markirte Zeitabschnitt der Lysis dient vortrefflich, um den raschen Entscheidungen zur glücklichsten Prognose, man darf sagen bis dicht vor die Grenzen der Reconvalescenz, das Romanhafte zu benehmen. Denn es möchte scbwer fallen, mit nüchternen Gedanken sich die nothwendige Rückbildung so mannig- 
facher Solidarverbildungen in den Geweben vorzustellen. Dafür tritt aber nachhelfend hier der Zeitraum der Lysis ein, und in der That entbehrte der vierte Fall, nämlich der frischeste, wo jene Verbildungen erst in der Entwicklung begriffen waren, desselben fast zum Unmerklichen. Während dieser Periode von eben so langer oder noch längerer Dauer, als die erste sturm- und drangvolle, begreifen sich die allmähliche Rückbildung der Drüsenverbildungen, unmöglich obne Resorption alienirter Stoffe, die langsamere Verbrennung von Krankheitsresten, die successive Ausscheidung der noch unvollkommen oxydirten Flüssigkeiten. Aber eigenthümlich bleibt die Indifferenz des Kranken gegen die fieberhaften Steigerungen dieser künstlich geschaffenen oder eingelegten Remittens, welche weder seinen Schlaf noch sein Nervensystem noch sein allgemeines Wohlbefinden beunruhigten, wenn sie nicht, wie in Falle 2, eine ausserordentliche Höhe im raschen Vorübergehen erreichten. Ein Beweis, dass die krankmachenden Elemente von acuter oder intoxirender Schärfe, wenn ich mich so ausdrücken darf, bereits abgestumpft, ausgeschieden oder durch eingeleitete Zersetzung unschädlich gemacht waren.

6) Lehrreich ist ferner das baldige Aufhören der bekanntlich in den ersten Stadien so verrufenen Blutungen aus der Nase in 2 Fällen, also abermals eine schwer verdauliche Zeugschaft zur Anklage des verrufenen Sublimats wegen „Beförderung der Blutzersetzung", da über ihren „adynamischen" Charakter Niemand zweifeln wird. Auch die ausserordentlich rasche Abhebung des grossen Brandschorfes im zweiten Falle mittelst der üppigsten Granulationen könnte den doctrinären Gegeneifer etwas stutzig machen, wie die sodannige völlige Abheilung der Wundfläche binnen $9-10$ Tagen ohne Schmieren und Salben in einem mit "Mercurialgift" gebeizten Körper. Alle medicamentöse Aeusserlichkeiten sind beim typhösen Decubitus, wie bei vielen andern schlechten Wundflächen, eitel Kram, wenn sie nicht, "von lnnen heraus heilen“, d. h. so lange ein entmischtes Blut keine bessere Zellennahrung zu bieten vermag. Die erstaunlich rasche Besserung und Heilung des brandigen Decubitus hängt in der Ursache mit dem Schlafe und mit den Hautschweissen eng zusammen, und könute nicht minder auf den Namen Krise Anspruch erheben.

7) Den allen 4 Fällen gemeinsamen frühen Vorzeichen der 
Salivation, glücklicherweise aber erst zu einer Zeit, wo, aus dem weiteren Verlaufe zu schliessen, die längere Fortsetzung des Mittels unnöthig geworden war, wüsste ich bis jetzt keine Bedeutung zu Wohl oder Weh beizulegen. Die Reaction der Speichelorgane erweist sich im Abdominaltyphus nach meinen bisherigen Erfahrungen weit empfindlicher, als bei Blatternkranken, um so sonderbarer, als ein gewisser Speichelfluss sich öfters bei letzteren spontan einstellt.

8) Individuell dürfte aus der Reihenfolge von entscheidenden Wirkungen des Sublimats auf den Abdominaltyphus bei einem ungefähren Durchschnittsverbrauche von 110 Gran hervorgehen, dass er metamorphosirend oder metabolisch direct in das Blut greift, und dass sich daher die soliden Veränderungen im Darm, Lungen u. s. w. hinsichtlich ibrer organischen Influenz und Wichtigkeit nur wie secundäre Theilprocesse zum capitalen Focus im Blute und in Zellensäften verbalten. Es giebt aber noch genug zu denken, dass der Sublimat in sehr verschiedenen Krankheitsstadien, wo seine erste Anwendung hier zum Treffen kam, den typischen Cyklus, wie wir jhn beiläufig auf $3-5$ Wochen zu ästimiren pflegen, geradezu zu durchbrechen vermag, während er in den Blattern, auch in den modificirten, wenn sie sich noch beiläufig an die Schnur Sydenham's hielten, daran nichts Merkliches änderte, und das gewiss zum Heile der Kranken.

9) Bedeutungsvoll bezüglich eines der Angriffspurikte des Sublimats ist die rasche Erniedrigung des Pulses in dem vierten, melir $z$ wischen Crisis und Lysis schwaukenden Falle unter die Normalzahl. Diese Erfahrung steht nicht isolirt, indem sie in 3 früheren ebenfalls mit Sublimat, aber schüchterner, behandelten Typhusfällen von einem mehr schleichenden Character ebenfalls zum Vorschein kam mit einem Sinken des Pulses auf 60, ja einmal sogar auf ein ängstliches 50 . Auch bei diesen hatte schon von vorn berein das Missverhältniss zwischen geringer Pulssteigerung und hohen Temperaturen statt, und konnte also die Wirkung des Sublimates auf die Ermässigung der Herzschlagfrequenz um so merklicher und isolirter hervortreten. Diese directe Wirkung auf das Herz, welcher viele meiner Sublimatversuche in anderen Krankheiten beitreten, erinnert augenscheinlich an die der Digitalis. So wechselt also dasselbe Typhusgift im Blute mit seinen Affectionen der einzelnen 
Nervenprovinzen je nach individueller Disposition, und öfters nach den verschiedenen Phasen des Krankheitsverlaufs, bald unter dem Gepräge der vorherršschenden Delirien, bald des Sopors, bald der motorischen Erregungen des Rückenmarks bei freierem Gehirn. So ist auch am Herzen die lebhafteste Bewegungsfrequenz zwar die Regel, aber es giebt auch den Contrast seiner relativen Trägheit unbeschadet hoher Temperaturen.

Das Arzneimittel hat uns also mittelst seiner Erfolge unschätzbare Blicke in die Art und Weise, mit welcher der Abdominaltyphus einer raschen Heilung gleichsam methodisch entgegengeht, und in die successiven Bedürfnisse von Secretionen zur organischen Restitution eröffnet. Man wird mir daher nicht verargen, wenn ich im Vermissen dieses Augeuscheins an der erkältenden Methode, übrigens der theoretisch plausibelsten von allen bisherigen Heilversuchen, welcher ich selbst mit einem erschütternden Sturzbade meine Rettung aus einem zu Warschau im Jahre 1831 erlittenen Typhus desperaten Anscheins zu verdanken glaube, nur einen symptomatisch-temporisirenden Werth zugestehe. Aus den Vorgängen, mit welchen das Arzneimittel von den krankhaften Verirungen den organischen Haushalt nacheinander zurückführte, wird Mancberlei auf positive Weise erfabren, was manche Streitigkeiten der allgemeinen Pathologie zurechtsetzen könnte. Z. B. möchten die älteren ärztlichen Schulen mit ihren Ansichten von der prästabilirten Bestimmung des Fiebers und seiner accessorischen Akte zur "Reinigung des Blutes" der Wahrheit weit näher gekommen sein, als die neuere rationelle Speculation, welche sich rundweg über solch teleologischen Quark moquirt. Das Fieber wird eben doch ein natürliches Hilfsmittel bleiben müssen, freilich kein bewust wählerisches, keines im Sinne einer Lebensversicherungsanstalt, aber immerhin eine vorgeordnete Mitgift zu Schutz und Trutz aus dem Vorrathe jener Weisheit, vor welcher ein Geist wie Stahl bei der scharfsinnigsten Einzelausdeutung in Krankheiten auf die Knice fallen heisst. Kein Arzt seit ihm hat eine solche Füle apollinischer Blicke in die labyrinthischen Gänge des krankhaften Lebens und in die natürlichen Ressourcen zu ibrer Ausgleichung gethan. Keiner hat den Gedankeubesitz unserer „bewussten“ Seele so ernst auf den Weg der Bescheidenheit vor jener vorsichtlichen Weisheit gewiesen, welche er seinen „unbewussten“ Seelentheil im Krankheitsgebiete ent- 
falten lässt, wie dieser Mann in seiner halb vergessenen "Ratio medicinae".

Aus Boerhaave's excentrischem Rufe: „0 könnte ich Fieber. machen! " tönt in einer grossartigen Andacht ein Echo Stahl's nach. Selbst dieser Superlativ hat in Gedankentiefe viel vor Jenen voraus, welche mit temporärer Unterdrückung der allzu heftigen Aeusserungen des Fiebers seinen inneren Fond a us zuheilen glauben möchten, ganz analog jener noch häufigern Ueberschätzung, welche mittelst äusserer Kälte locale Entzündungen aus innerem Blut- oder Nervenzwange in sichere Fesseln zu schlagen vermeint.

Mittelst der Probe derselben Sublimatbehandlung, woza ein glücklicher Griff auch zugleich das schickliche Maass im Quantum gefunden hat, wird ferner zu entdecken sein, wo es mit dem Petechialtyphus, richtiger Cerebraltyphus, in seinen krankhaften Secretionen, populär gesprochen, "denn eigentlich binaus will. " Gewiss liegt in seinem Exantheme so wenig als in der Roseola des Abdominaltyphus die wesenhafteste Ausscheidung. Möglich, dass er sich in solcher Haut- und Hirngluth ergeht, weil die Ausgänge nach andern Colatorien verschlossen sind. Der theoretische Gewinn und eine Reihe glücklicher Erfolge mit eben so constanten Folgeerscheinungen, wie bei den obigen Abdominaltyphen, wäre für die innere Natur der Krankheit und ihre nähere oder entferntere Verwandtschaft mit letzterem geradezu entscheidend. Denn entweder öffnen sich die Colatorien des Darms, der Leber, der Nieren zu ähnlichen präcipitirten Ergüssen mit ebenbürtigem Erfolge, dann wüssten wir, woran es bisher hemmend gehangen, und aus der Analogie der nöthigen Ausscheidungen resp. vorbereitenden Krisen würden wir die Wurzelverbindung beider, in so Vielem äusserlich divergirender Processe erkennen. Oder der glückliche Erfoly käme ohne solche secretorische Zwischenfälle, dann wäre der. Beweis für die direct entgiftende Operation des Sublimates im Blute geliefert und die innere Identität beider Krankheitsarten dennoch hergestellt, wenn auch die Verschiedenheit in den Ausscheidungswegen stehen bleibt. Sollte sich das Mittel wirkungslos oder schädlich erweisen, wobei in unserer heutigen Wehrlosigkeit eben auch nichts verloren wäre; dann möchte ein botanisches Krankheitsregister über die nächste Verwandtschaft behaupten, was es will, sie bliebe thatsäcblich eine sehr entfernte, Denn die sonstige Unsicherheit des Schlusses „ex 
juvantibus et nocentibus " lässt sich der gleichsam methodischen Constanz der Folgeerscheinungen aus dem heroischen Giftmittel in unsern Musterfällen nicht vorwerfen.

Wem etwa der Gedanke an eine einseitig-,,specifike" Wirkungsweise des Sublimates in den petechialen, und so weit er den sparsamen Zahlen trauen mochte, auch in den confluenten Blattern gekommen wäre, er wird ihn nach seinen Wirkungen auf den $A b-$ dominaltyphus sogleich wieder haben fallen lassen. Denn eben der "rothe Blutfaden ", welchen jch oben schon in den Anfängen der petechialen Blattern als eine potentielle Verbindungsschnur mit manchen andern grossen Krankheitssippen, namentlich wenn sie sich zum Schlimmen neigen, herausgegriffen habe, hatte mich ganz richtig und glïcklich auf. und durch den Typhus als ein Consimile geleitet. "Potentielle" Verbindung darum; weil hier oft dieses äussere Merkmal fehlt, aber jede der gedachten Gruppen häufig die Neigung zeigt, sich ebenfalls damit und mil anderen der inneren Blutzersetzung zugeschriebenen Zeichen anzuthun, so der Typhus, die Pyämie und die vielgestaltige Diphtherie, von welcher letzteren an dem Zweige des Hospitalbrandes ja der erste Siegesruf des Neulings ausging. Krankheitsprocesse, welche in Form und Verlauf so weit auseinander liegen, werden sich durch die unbestreitbaren Erfolge des nämlichen Mittels plötzlich genähert, und es drängt sich der Schluss auf, dass allen etwas Gemeinschaftliches, welches den glücklichen Angriffspunkt für das Giftmiltel bietet, zu Grunde liege.

Gegen diese Gruppen-Breite, als dem Sublimate zuständig, gibt es keine stichbaltige Einrede mehr, denn die bisherige a priori ist durch das klinische a posteriori für immer aus dem Felde geschlagen. Anders steht es aber hinsichtlich der Höhe der Grenzen, und der mannigfachen Formung und Artung in jenen Einzelgruppen, wenn gefragt wird, bis wohin das Mittel ergiebig reicht, von wo es vielleicht zu schaden anfängt, und was es von letzteren, sei es wegen örtlicher oder allgemeiner Complicationen, wirksam umspannt, was nicht. Darum beisst es mit Recht: "practica est multiplex." Das ist aber nicht die Aufgabe eines Einzelnen, sondern der Versuche von Generationen, mit welchen auch öfters der Charakter von Krankbeiten wechselt, obschon sie denselben Namen und dasselbe äussere Gepräge forttragen. Uebrigens scheinen schon aus meinen gedachten, numerisch nicht imponirenden Versuchsreihen, einige 
schwache Bleistiftlinien zur relativen Werthbestimmung des Sublimates in den Einzelgruppen aufzutauchen, für deren Endgiltigkeit ich aber ausschliesslich nur in den petechialen Blattern gutstehe. Sicher in den Anfangsstadien dieser, ungleich weniger sicher, obgleich allen ubrigen Kunstmitteln weit uherlegen, in der confluirenden resp. in der pyåmischen Gruppe, weit sicherer noch im Abdominaltyphus, wenn der Schluss aus den regelmässigen Folgeerscheinungen mehr gelten darf, als der aus statistischen Zahlen, endlich vollkommen sicher in den gewöhnlichen Formen des Hospitalbrandes, zur diphteritischen Gruppe gehörig. Letzlerer diene mir noch zum Erläuterungsbeispiele für das, was ich oben verschiedene Formen und Arten vorbehaltlich nannte. Ich habe selbst Pirog off nicht recht geglaubt, welcher von ungemeinen Verschiedenheiten in Form und Arten desselben spricht, bis ich an einigen für mich neuen den mir viele Jahre durch und durch bewährten Sublimat scheitern sah. Doch gesetzt, er würde in jeder Diphtherie der Wunden alles Erwünschte leisten, so würde daraus sich nichts weniger folgern lassen, dass dasselbe Grundübel an andern Organen, z. B. in den Kehlkopf als wirklich dipherit. Croup oder in den Mast- und Dickdarm als djphterit. Rubr u. s. w. versetzt, demselben Mittel pariren werde. Genug einstweilen, dass so viel Augenscheinliches, Unumstössliches vom Sublimate festgestellt ist, um die Interdikte, welche Andere von Controlversuchen abschrecken könnten, zu bescbämen - Zeit und Geduld werden das weitere Nötbige bringen.

Selbst die mässigsten Erwartıngen, welche man aus den obigen Vorgängen des Sublimates schöpfen möchte, würden hinreichen, seine nähere Wirkungsweise zu einem Probleme für die Thătigkeit der Physiologie und namentlich der organischen Chemie zu erheben. Noch weit mehr aber neigt er sich nach der physiologiseben Seite mil seiner Gewalt, die Resorption von flüssigen Exsudaten aller Art in einem unvergleichlichen Grade wach zu rufen und zu befördern; täuschte mich nicht Alles, so übte er dieselbe mittelst sehr energischer Einreibungen öfter sogar schon in desperaten Lagen frischer Thrombosen von Gefässen und fibrinöser Exsudate auf den Herzklappen. Aber der schlagendste Beweis dazu liegt darin, dass er in mehreren Bright'schen Kranken mehrjähriger Veraltung in derselben, aber weit schwächeren Form den allgemeinen Hydrops rasch vertrieb unter stromweiser Harnentleerung, leider in dem Ge- 
folge einer unbändigen verderbenbringenden Salivation, und bei einer Glücklicheren mit baldigster Recidive des Hydrops. Klinische Ehre war allerdings nicht damit einzulegen, das kann aber dem Physiologen gleichgültig sein. Und gerade in dieser ausserordentlichen Kraft sind auch die Gefahren für die ärztliche Anwendung begründet, wenn sie die oft so schwer zu erkennenden Grenzen uberschreitet, wo es freilich besser gewesen wäre, ältere schlecht geartete Exsudate ihrem Schicksale z.ı iberlassen, anstatt mit ihrer rascheren Aufsangung Stürme aulzuwiegeln, denen weder die gesunkenen Kräfte, noch ein gewisses Desinfectionsvermögen des Mittels mehr gewachsen sind. Missgriffe dieser Art werden noch lange nicht ausbleiben, und auch ich habe damit persönlich ein theures Lehrgeld bezahlen müssen. Aber sie sollten bei vernünftiger Betrachtung von der Potenz des Mittels an und für sich getrennt, ja vielmebr als Zeugnisse derselben auf irrigen Wegen gewürdigt werden, statt das hundertmal positiv Wohlthätige und Unentbehrliche über einzelnen Niederlagen bei seinen Ueberbietungen a priori zu beeifern oder wegzuwerfen. Das heisst nicht mehr kluge Vorsicht, sondern blinde Furcht und Schrecken.

Surnmarisch genommen werfen sich also in den vieljährigen Phasen meiner klinischen Sublimatversuche bei 3 verschiedenen Anwendungsformen - innerlich, Einreibung, Umschlag - 2 therapeutische. Grundkräfte, eine desinficirend metabolische, und eine resorptionsbefördernde heraus. Die erstere trat am frühsten zu Tage bei dem Hospitalbrande der einst famosen Malaria von Germersheim, hald darauf an pyämischen Zufällen in anderer Verbindung, die zweite später und in allmählicher Verbreiterung mit aufsteigender Kühnheit in der Gabe. Die erstere Hilfseigenschaft verbreiterte ibr siegreiches Versuchsfeld so ungemein erst in der neusten Zeit. Sie können sich wohl denken. dass ich mitten unter solch neuen Effecten im Hypothesiren und Patherholen aus fremden bezüglichen Forschungen, worunter insbesondere auch Ihre grossen Arbeiten uber fibrogene Substanz und Thrombose mich fesselten, nicht faul sein konnte.

Parallel $z u$ diesen 2 Grundkräften verfolgten- meine Gedanken auch zweierlei Richtungen oder Zielpunkte, für die metabolischdesinficirende Kraft auf das Blut, für die resorptionsteigernde zunächst auf die Herzthätigkeit. Bei dem Visiren nach jener handelte 
es sich, damit es nicht bei einer vagen Redensart bleibe, um die Auffindung eines näheren Angriffspunktes für das Mittel im Blute, mit anderen Worten einer fasslichen Causa movens seiner endlichen Wirkung, welche auch Elasticität genug besitze, um über die neusten Eroberungsgebiete contagiöser Natur ausgedehnt werden zu können. Jene war vermöge neuerer objectiver Forschungen nicht $\mathrm{zu}$ erfinden, sondern es war sich nur mit eigenem wesentlichen Beitrage für eine der bereits gebildeten Parteien zu entscheiden mittelst Assimilation der Heilerfolge zu ihrem Standpunkte. Zu ihrer Stütze hielt ich insbesondere einen Beitrag für wesentlich, welcher, wenn nicht das Räthselhafte völlig zu erklären, doch verständlicher zu mächen im Stande wäre: warum sich die entschiedene Wirkung des Sublimates lediglich auf das Anfangsstadium der petechialen Blattern begrenzt, und warum im Zusammenhange damit erst nach dem Verwischen der örtlich petechialen Marke das eigentliche Exanthem zur normalen Entwicklung mit glücklicher Reife, ohne spätere Recidive in das Petechiale, gedeihen kann. - Ich denke diesen Nachtrag von kürzester Fassung in einer eigenen Schrift bald zu geben, welcher der vorliegende Aufsatz, wie er ist, als faktische oder praktische Unterlage abdrucksweise dienen soll.

Für diese Schrift habe ich auch die nähere Rechenschaft über die Steigerung der Resorption durch den Sublimat aufgespart, welche jch der Wiederaufnahme meiner Studien an der Herzthätigkeit verdanke. Letztere sollen ihren Mittelpunkt ausmachen, und wird ihnen ein kurzer Faden meiner Sublimatversuche nach anderer Krankheitsrichtung mit aphoristischen Einzelmotiven vorausgeschickt werden. Dieser zweite Theil des Ganzen wird sich an den Herrn Professor Skoda in Wien adressiren, Niemand hat mehr Anspruch auf diese Widmung, als er. Nicht allein, dass ich ihm eine öffentliche Revanche für etwas schiefes Licht schulde, in welches ihn meine Empfehlung zur Gewährung von bekannten Sublimatversuchen an melureren trostlosen Fällen des Wiener Krankenbauses vor 2 Jahren gesetzt baben mag, sondern, weil er sehon vor 25 Jahren meine bezügliche Ueberschwenglichkeit für Pneumonieen durch stille Controlversuche in seinem grossen Wirkungskreise mit strenger Güte zu dämpfeu bemüht war. Hätte es eine Erfahrungsmacht in der Welt gegeben, welche mir Glauben und Hoffnung an etwas wurzelhaft Souveraînes im Sublimate hätte verleiden können, so wäre es die- 
ser scharfsinnigste, verdienstreichste und in seinen umsichtigen Prüfungen oder Nachprüfungen wahrhaftigste aller medicinischen Skeptiker gewesen. In vieler andern therapeutischen Skeptik waren oder wurden wir längst eìnig, in Zielen des Sublimates, obschon ich ihm so manche Abkühlung des Heisssporns dankbar zugestand, blieben wir, wenn sein Messer an meine Hoffnungen auf eine fernere Versuchswelt gehen wollte, die geschiedensten Gegner. Gegen einen solchen Saulus nach rastlosen Sorgen und mancherlei Verirrungen gerade auf dem unwahrscheinlichsten sog. skorbutisehen Boden der Blattern ein unumstössliches Recht vion dèn ausserordentlichsten Consequenzen errungen zu haben, schätze ich mir zur höchsten Ehre meines ärztlichen Handlungslebens:

Lange bevor physiologische Specialversuche den Sublimat als ein "Herzgifl" qualifieirten, zeigten mir die Versuche am Krankenbette im Fieber und in der Steigerung der Resorption Erscheinungen, welche ohne seine directe Gewalt auf das Herz und seine Bewegungsacte ganz unverșländlich waren. Dies reiẓte mich um so mehr, von dem Päthseln am Herzstosse nicht abzulassen, welcher vielen Physiologen als ein ziemlich bedeutungsloses Accidens erscheint, von mir aber, seit ich über Herzbewegung selbstständiger dachte, für den wahren Schlüssel zu den labyrinthisch verschlingenen Herzacten gehalten wurde. Die Rückstosstheorie Skoda's befriedigte mich nie, weil sie mir, trotz ihrer Sicherheit von physikaliseher Seite her, nicht den mindesten Aufschluss über die häufigen Widersprüche in Krankheiten zwischen tumultuarischer Stärke des Herzstosses und Schwäche der Pulse bei normal gebautem Herzen zu geben vermochte. Aus einem muskulösen, also allen möglichen Schwankungen ausgesetzten und dennoch von der Herzcontraction zu isolirenden Acte musste derselbe hervorgehen, wenn seine Erklärung den klinischen Erfordernissen gerecht werden sollte.

Die Papillarmuskeln meines früberen Versuches in einér lithographirten Abhandlung vom Jahre 1840 hatte ich nicht etwa wegen des witzigen Spottes von Skoda oder wegen des groben von Kürschner, dessen bezügliche Versuche an Thieren die heutige Experimentirkunst mit schallendem Gelächter begrüssen würde, nicht wegen der anatomisch-physikalischen Unmöglichkeit ihrer Beihilfe, sondern wegen der allzu geringen Ergiebigkeit ihrer Wirkung in der nothwendigen Richtungslinie aufgegeben. Damit aber entsagte. 
ich keineswegs meiner alten dort ausgesprochenen Zuversicht - dem eigentlicben Punctum saliens jener Abhandlung - dass die Kammerbewegung sich zeitlich und räumlich in mehrere Acte gliedere, welche nur wegen der Schnelligkeit der Aufeinanderfolge und des Ineinandergreifens unseren Sinnen entgehen.

Diese Einzelacte mussten durch besondere muskuläre Componenten mit einer itio in partes vertreten sein, und unter ihnen war nach einer anatomischen Gruppe zu suchen, welche über alle $\mathrm{Er}$ scheinungen und Folgen des Herzstosses mit vollerer Kraft als die Papillarmuskeln Rechenschaft zu geben vermochte. Dort oder nirgends mussten die nächsten Anbaltspancte für die Einflüsse des Herzens auf die Resorptionsthätigkeit gesucht werden. Nachdem ich mir diesen Brennpunct der Kammerthätigkeit fixirt hatte, ordneten sich ihre übrigen 0perationen gleich Postulaten in Reihe und Glied des Ineinandergreifens.

Es fehlt aber auch bis heute nicht an den grellsten Widersprüchen literarischer Autoritäten über die Conformation der Papillarmuskeln und über das Niveau der Atrioventricularklappen am Ende der Systole. Von deren Gestaltung, von welcher wieder die ganze äussere Form der-Kammern in diesem Momente bedingt wird, hängt aber ein geordnetes Zustandekommen der Diastole ab. Ueber das diastolische Klappenspiel gleiten die bisherigen Ansichten sehr oberflächlich hin, obwohl die Schwierigkeiten seiner, den mechanischen Forderungen gerechten Verständlichung wenig geringer sind, als die der Motive zum Herzstosse. Erst mit einem klareren Sehen in den diastolischen Klappenmechanismus lässt sich die Nothwendigkeit eines zweiten in und von der Kammer selbst gebildeten Herztones einsehen, welche Skoda immer behauptete, deren Hilfsvorgänge er nicht zu ergründen vermochte.

Experimenten an Thieren sind alle diese inneren Kammervorgänge wegen ihrer Flüchtigkeit unzugänglich. Mechanischer Combinationssinn muss sie ersetzen, immer zugleich gefügig der Fälle von anomalen Erscheinungen, in deren monumentaler Auseinandersetzung der Altvater der physikalischen Untersuchungsmethode für Deutschland schwerlich je erreicht, geschweige übertroffen werden dürfte. Wo aber meine mechanischen Beordnungen den seinigen zuwiderlaufen, mag er mein Bekenntniss zur Genugthuung hinnehmen, dass beziggliche Combinationen anderer Forscher mich auch 
nicht entfernt ähnliche Mühe zur Widerlegung gekostet haben, als seine streng und tief durchdachten Thesen.

Doch konnte ein alter Grübler an Nerven - und Muskelthätigkeit nicht so viele Jahre an dem mechanischen Haushalte dieses "idealen" Muskels verweilen, obne gleich dem Fischerknaben Göth e's, aber mit grauen Haaren, nochmals von der Wassernixe auf ihren geheimnissvoll "wohligen" Grund gezogen zu werden. Mehr noch als die Physiologie fühlt der klinische Arzt aus einer Menge von Erscheinungen, welche vorühergehend auf das Täuschendste Veränderungen im organischen Herzbau simuliren, wie wenig noch selbst mit einer perfekten Kenntniss der mechanischen Acte obne einen näheren Blick in die nervöse Dynamik hier gethan sei. Bej dem Vertiefen in die nervöse Gangliensphäre galt es vor Allem, einen Ankergrund über die Grundlrage von "automatisch" oder "reflectiv" in den Bewegungstrieben des Herzens zu suchen, welche dem Arzte zur Erklärung der mannigfachen Compensationsvorgänge bei organischen Herzveränderungen so dringlich nahe gerückt wird, dass der Automatiker versucht werden mag, vor Staunen über die Zweckmässigkeit der Nachhilfe an eine Intervention der Seele Stahl's zu appelliren. Da war es nicht mehr das klinische, sondern das ausgeschnittene oder theilweise unterbundene Herz mit den klassischen physiologischen Versuchen daran, von welchen die denkende Betrachtung anheben musste. Einen noch wenig benutzten Ueber-. gang zum Herzen, welches noch im Zusammenhange mit den liöheren Nervencentren steht, bildete jener in der Literatur einzige Fall eines periodischen Stillstandes des normal gebauten Herzens, welcher der Gegenstand einer längeren Beobachtung von Skoda, damals Secundärarzt, und mir auf dessen Abtheilung im Herbste 1833 war. Ich hatte conjectural ein Pseudoplasma an einem Herznerven diagnosticirt, welches sich denn auch mebrere Monate nach meiner Abreise unter dem Messer Rokitansky's am Nerv. card. magn. vorfand. Meine Veröffentlichung in Müller's Archiv geschah erst 1841. Diesem klinischen Vorspiele folgte alsbald der weltberühmte Versuch Weber's am Vagus, unter dessen Eclat jene aparten und grässlichen Thatsächlichkeiten und meine Schlüsse daraus übersehen oder nicht weiter verfolgt wurden. Die Weber'schen Versuche sagen begreiflich nichts über die furchtbaren Schmerzen aus, welche den klinischen periodischen Stillstand mit dem Vorgefühle 
und der Voraussage seines Herannahens auszeichneten, und umgekehrt war aus diesem noch nicht zu errathen, ob das Herz sich währenddem systolisch oder diastolisch verbalten habe. Durch die exorbitante Schmerzhaftigkeit ist aber die mittelweilig fortdauernde Communication der sensiblen Herznervenpartie mit Gehirn und Rückenmark verbürgt, und darum durfte ich diesen Fall als Uebergang rom gewissermaassen motorisch unterbundenen, sensibel freien Herzen zum weiteren Forschen an den normalen Nervenfactoren des Herzens, an ihren Einzelleistungen und Gegenleistungen, weiter verfolgen und ausbeuten. Neben manchen Blössen und Unzulänglichkeiten des Lehrsatzes von Bell, wie er zur Zeit liegt, eröffneten sich mir neue Gesichtspuncte über eine eigenthümliche Anordnung der Herznerven wie über die sehr verschiedenen Lebensäusserungen der Herznervenpartieen in ihren engsten Beziehungen zur Muskelzelle, welche mir die Ursache des muskulären „Perpetuum mobile“ (mein Vater war ja ein "Schwabe") verständlicher machten. Auf objective Beweiskraft machen diese Originalideen keinen Anspruch, ich möchte sie deswegen gleichsam nach dem Vorgange Bell's erst für „Freunde gescbrieben " erklären, aber ich halte sie, sinnlich klar wie sie einerseits, und häretisch fermentativ, wie sie andrerseits sind, des Augenmerkes von Physiologen und Physikern zur näheren Prüfung würdig. Ein Ludwig, meine ich, sollte sich finden, um ihnen experimentell die starken oder schwachen Seiten abzugewinnen.

So weit wären meine Herzacten geschlossen und fertig. Ob ich das für das dortige organische Nervenleben Erdachte auch auf das animalische in den willkührlichen Muskeln gleichzeitig zu übertragen versuchen werde, wozu der Tetanus, die Volta'sche Alternative, das Atropin in dem Auge, andrerseits das Curare nur zu sehr mit Analogieen reizen, weiss ich zur Stunde noch nicht. An das nervöse Bewegungsspiel des Herzens lässt sich mit schismatischen Anschauungen sicherer gehen, als an das willkührliche, wo es die galvauischen Versuche bereits zu einer physikalischen Feinheit und Exactheit gebracht haben. Keine neue theoretische Conjectur darf sich in Widerspruch mit diesen Ergebnissen setzen, und da füble jeh denn sehwer, dass mir in der Lage eines von solcbem Umgange isolirten Gedankenmenschen die Verständlichung mit einem Physiker höherer Rangordnung noch abgeht. Doch vielleicht wage ich den Sprung ohne diese Cautele, also auf die Gefahr hin, aus unzuläng- 
licher Einsicht in die höhere Electricitätslehre und Technik mit letzteren etwa zu collidiren, im Vertrauen auf ein älteres Heimathsrecht in einem noch nicht gelösten klinischen Probleme, welches sowohl Berührungspuncte genug mit älteren und neueren galvanischen Versuchen hat, als in Ursache, Procedur, Heilung einen wie absichtlich geschürzten Knoten von Geheimnissen des Muskel- und Nervenlebens vertritt. Ich meine die kramplhafte Muskelcontractur, welcher es namentlich in den ersteren Stadien an tetanischen Paroxysmen mit der lebhaftesten Schmerzsteigerung nicht fehlt, welchem Allem mit Durchschneidung ein, wenn auch oft nicht beständiges, aber sicherlich zeitweiliges Ende gemacht wird. Wenn aber schon sogleich jenseits der einfachen Erklärung der tetanischeu Schmerzsteigerung namentlich auf Extensionsversuche mittelst Reflex für den damit nicht zu Sättigenden bis jetzt kein Weiterkommen ist, so stehen wirklich nach dem Sprichworte "die Ochsen am Berge", wenn aus der Tragweite unserer heutigen Nervenlehre eine nicht genug zu dankende Wahrnehmung Stromeyer's genügend erklärt werden soll, nämlich: dass sich selbst nach Durchscbneidung der nervenarmen Sehnen ein mehr oder weniger weit verbreitetes Gefühl von Torpor in der Umgegend einstellt, gewiss in seinen nächsten Ursachen zusammenhängend mit der längeren Erschlaffung des durchschnittenen Muskels, ohne welche das Zusammenheilen der Muskel- oder Sehnenenden vielfach gestört werden miisste. Diese böchst befremdliche Erscheinung ist begreiflich nur dem krampfhaftschmerzlichen Stadium verbunden, ist aber keineswegs der Messeroperation eigen, obwohl sie hier in ihrer vollsten Reinheit und Autorität hervortritt. In Nachahmung der väterlichen orthopädischen Manipulationsweise an solch verkürzter Muskulatur habe ich dieselben vorübergehenden Erfolge, d. h. Welkheit und Taubbeit, unter meinen eigenen Augen constant bemerkt.

Sonderbarer Weise trafen schon vor mehr als 30 Jahren Henle und ich, obwohl uns damals noch ferne und fremd, in Bemühungen um die Lösung dieses gehejmnissvollen Knotenpunktes längere Zeit zusammen. Ich für meinen Theil suchte in dieser Enträthslung zunächst die physiologische Haft zur scientifisehen Rechtfertigung der von meinem Vater J. Georg Heine reformirten mechanischen Orthopädie, und zur verdienten Rebabilitation seines bereits in Deutschland schmählich verkommenen Andenkens. He nle stand 
in dieser Beziehung auf ganz neutralem Boden. Aber beide waren wir der Ueberzeugung voll, dass bei einer gründlichen Einsicht in die Ursächlichkeiten dieses Phänomens sich ein strahlendes Licht uber das Nervendunkel im vitalen Verbande von sensibeln und motorischen Nerven verbreiten müsse. Mich hatte im Durchgange durch mein woblbegründetes "Fixationsgesetz der Muskulatur" ein Zwielicht zu dem vermeintlicben ,Belastungsgesetze der sensibeln durch die motorischen Nervenmassen" verführt. Doch was geht über Streben und Mitstreben jüngerer Tage selbst in seinen Irrthümern und Ueberstürzungen? Noch heute stehen mir jene schwellenden Auguststunden des Jahres 1842 frisch vor der Seele, wo wir im Geleite des Freundes Pfeufer bei längerer Fahr über den Züricher See unter der ersten Mittheilung meiner Gedankenreihe über das zergliederte Pbänomen die Reize des Alpenhimmels und der lachenden Uler vergassen. Ich habe nunmebr einen andern Model von ungleich schärferem Gepräye, welcher dem Nervenleben des Herzens entnommen sich mit einer gewissen Modification auf sämmtliche oben gedachte Erscheinungen in deu willkürlichen Muskeln miterstreckt, zur Begehung desselben Problems gefunden. Möge dann dieser einst mit Vorliebe pathologische Denker seinen Prüfstein abermals daran freundlichen Andenkens versuchen!

Doch wenden wir uns von diesen idealen Aspekten, wo Niemand vor einem dädalischen Schicksale behütet ist, noch mit Einem Blicke auf den unerscbütterlichen Boden der rettenden That, zu dem Kerue dieses Aufsatzes, zurück. Es war hohe Zeit, dass ein solcher Hahnenruf, wie der aus Blattern und Typhus, zu neuem Glauben und Hoffnung in die noch unerschlossenen Kräfte der inneren Medicin erging, weil jene noch $z \mathrm{u}$ keiner Zeit im strebsameren erfahrenen Theile der auf das Handeln angewiesenen Aerzte so arg kränkelten. Warum noch niemals in solchem Grade? Weil die Diagnostik, d. h. die Kenntniss der äussern Krankheitsformen und Zeichen, etwa seit 50 Jahren nach allen Seiten hin Riesenschritte gemacht hat, und die therapeutischen Fortschritte. vergleichsweise einen Schneckengang einhielten mit vielfáchen von einer rationellen und experimentellen Skepsis nach rückwärts gebogenen Curven. Was an höherer pathologischer Erkenntniss gewonnen das dagnostische Bereich überschritt, sah sich bei einem Blicke auf die arzneilichen Hilfsmittel und auf ihr Verständniss gelähmt und verlassen, oder den Wald 
vor lauter gemalten Bäumen nicht. Ich nannte darum längst in meinen. "Studien" unsere ärztliche Periode die der "Scientia mali" ohne die "Scientia boni", tröstlich darüber, weil man erst sich zu einer besseren Erkenntniss der krankhaften Objecte hinaufarbeiten müsse, ehe die Morgenröthe eines krüftigern Heilvermögens anbrechen werde. In der That wäre für das wissenschaftliche Begehren eines Arztes mit einem in diesem und jenem Krankheitsreviere noch so kräftig fördernden neuen Heilmittel wenig gewonnen, wenn die Diagnostik am Krankenlager und an der Leiche noch in einem ähnlichen bunten Haufen durcheinander läge, als in den ersten Jahrzebnten dieses Jahrhunderts. Heute aber, wo die diagnostische Bahn mittelst wunderbarer Arbeiten geebnet, die Vorhalle zum Krankheitsinnern geöffnet ist, wird ein in seiner chemischen Zusammensetzung, in seinen physiologischen Wirkungen bekanntes Heilmittel von heroischer Kraft neben seinem philanthropischen Werthe um so mehr zur feineren Sondirung der geheimeren krankhaften Vorgänge, Bedürfnisse, und des organischen Zusammenhangs $z$ wischen mancherlei Krankheitswurzeln dienen, mit andern Worten, das Heilwerkzeug wird zugleich ein biologisches Erkenntnissmittel abgeben können. Auch in ihm tritt der praktische Utilitarismus vor der höchsten freilich unendlichen Aufgabe der Medicin, dem Organismus auf allen seinen Verirrungswegen in der reichsten Entfaltung aller seiner Leidenschaften und Widerstandskräfte zu folgen, und so ein volles Bild des Lebens mit den Gesetzen des Werdens und Seyns zusammenzusetzen, in den Hintergrund. Ich sagte, selbst der zeitliche Utilitarismus steht jener Aufgabe hintan, das ist auch für die practischen Desiderate der Zukunft wahr. Denn wer weiss, was von unsern gefeiertsten Mitteln, den Neuling Sublimat selbstverständlich miteingeschlossen, vor den Fortschritten streng wissenschaftlicher Erkenntniss noch lange hält? Die auf directem Wege, nicht auf empirischen Umwegen, zufliessenden Heilgaben werden vielleicht von einer Art, dass all unser bisheriges Material als ein spielerischer Durchgangspunkt erscheint. Ich für meinen Theil würde den eigenen Fund des Sublimates verwünschen, wenn er in falscher Selbstberuhigung zu Bader- und Receptur-Sinn jene höchste, heiligste Potenzialität der Medicin, welche die heutigen Strebungen in Deutschland mehr als je durchgährt, mit der Schmeichelei einer Circe: „Verweile doch, hier ist's so schön, " auch nur Einen Augenblick sistiren 
möchte, statt ihr einen frischen Sporn zu geben. Wie ich das meine, glaube ich einstweilen in flutchtigen Unrissen au der Verfolgung des Abdominaltyphus, und mit demjenigen, was ich von Gedankenarbeit am Herzen versprach, angedeutet zu haben. Denn zu den letzteren Forschungen gaben eben positiv ständige Erfolge des Sublimats in anderen Richtungen eices meiner ständigsten Reizmittel ab.

Ueberdies leidet kein gelehrter Stand bei seinen scientifischen und praktischen Bewegungen unter verkümmerten und kümmerlichen Ansichten der modernen Laienwelt so sehr, als der ärztliche. Auch nach dieser Fronte hin war zur Beschämung der letzteren ein solcher Ruck dringlich an der Zeit. Als geistigen Culturstand lässt man uns fast ausscbliesslich nur mebr in jenen Ausflüssen gelten, welche greifbar Nützliches d. h. unbestreitbar Heilsames zu Markte bringen. Von jener unendlich fruchtbareren Seite der ärztlichen Gebärmutter, welche bach Aristoteles die erste Philosophie und nachweisbar später die fortlaufenden Sprossen za den positiven Naturwissenschaften ablegte, wird aus geschichtlicher Unkenntniss oder aus mangelhaftem Verständniss für das unvergängliche Tauschverhältniss zwischen höherer Medicin und Naturlehre leichthin Umgang genommen. Seit der Majorennität der Naturwissenschaften, meint man selbst beim Zugesteben der früheren Fruchtbarkeit, sei sie für immer erloschen, oder rein überflüssig geworden. Dass Kräfte, welche den Makrokosmus bewegen, in ihrer Erscheinung am Mikrokosmus durch ärztliche Sehkraft und Tiefsinn fort und fort eine verständlichere Sprache für die Naturwissenschaft erlangen können, gilt dieser Oberflächlichkeit als fabelhaftes Hirngespinnst. Sie versteht sich ja in diesen Dingen weit besser, als ein Physiker wie John Tyndall, welcher es sehr natürlich findet, dass die grösste grundsätzliche Entdeckung in der Naturwissenschaft - die gegenseitige Auswechslung der Kräfte ohne Verlust an ihrer Summe von einem Arzte erhoben worden sei, weil dessen tagtägliche Beschäftigung ihn mit diesem Wechselspiele des Organismus in die nächste sinnliche Berührung bringe. Der Mensch und des Menschen Werth, in dessen Eingeweiden der Arzt nistet, ist und bleibt nicht nur das höchste und letzte Ziel der ganzen Naturkunde, sondern zugleich eine Orakelstätte, wo oft genug die rhythmischen Vorklänge zu ihrem späteren Wissen von einer auserlesenen Schaar orphischer 
Priester zuerst erıauscht, und jenes gesetzliche Wissen alsdann in dankbaren Mit- und Nachklängen gefeiert und volltönender gemacht wird.

Nach dieser relativ beliebigen Entkleidung von ihrer unveräusserlichen Lebens- und Entwicklungseigenschaft kommt die Heilkunde vor dem gleich hausbackenen Sinne nicht besser weg, wenn es sich um die Werthschätzung ihrer rein praktischen Gemeinnützlichkeiten handelt. - Der Philister glaubt steif und fest, ein "Grundrecht". an die Heilkunde zur Wiederherstellung seiner Gesundheit zu haben, wie eines an die Natur zu dieser Mitgift, die Heilmittel für alles Mögliche lägen in den Taschen der Schüler, eventuell auch der alten Weiber fertig und unfehlbar zur Bereitschaft; es bedürfe nichts als eines mehr oder weniger geschickten oder zufälligen Griffs, das eben Rechte herauszulangen. Da bedarf es denn freilich weder der Anerkennung eines höberen geistigen Waltens in der gelehrten ärztlichen Technik, noch einer achtungsvollen Pietät vor ihrem geschäftlichen Wirken. Es ist dann natürlich, dass die leersten Prätentionen im geraden Verhältnisse zu den reicheren Gaben des Angebotes steigen. Einen faktischen Beleg dazu liefert die böhere Chirurgie, welche von solchen seit den letzten fünf Jahrzehnten überströmte, und in ihren operativen Ressourcen auf streng wissenschaftlicher Grundlage vergleichsweise gar njcht mehr zu erkennen ist, einen ähnlichen die Medicina forensis in ihren diagnostischen. Ob man es beiden in äusserlicher öffentlicher Consideration ihrer praktischen Lebensstellung zu danken weiss, wird sich gleich notorisch erweisen. Von der gesammten Heilkunde wird immer mehr eine Lebensversicherung verlangt; so lange sie nicht dafür bürgen kann, dürfte sie sich fast für eine Amnestie wegen ihrer Unsicherheiten bedanken, könnte sie aber bürgen, so erschienen die Leistungen dennoch wie eine handwerksmässige Schuldigkeit, nicht wie eine göttliche Inspiration, nicht wie eine menschliche Befreiungsthat der Gesellschaft durch geistige und seelische Anstrengungen errungen.

Es ist kein erfreuliches Zeichen weder von der humanen Innigkeit, noch von einer poetischen Naivetät, noch von Verstandestiefe in unserer zeitlichen allgemeinen Bildung, dass diese platte und undankbare Anschauungsweise von der Heilkunde immer mehr die öffentliche Meinung beherrscht und sogar in der Gesetzgebung das grosse Wort bereits an sich genommen hat. Als Bichat die neuere 
Versuchsepoche der Physiologie und Pathologie mit seinem Werke "Sur la vie et la mort" begründete, dachte er wohl nicht, dass dieses feierliche Thema jemals wieder in den höheren praktischen Bemühungen um dasselbe bei dem Gewerbstitel untergebracht, dass abermals mit dem Ausscheiden von den "grünen" Fakultätsstudien in's praktische Leben die selbst von der Scholastik respectirte „ars liberalis" in den banausischen Gewerbskittel gesteckt, dass also der Geldlohn und nichts als der Geldlohn die gesetzlicbe Signatur dieses Standes werden könnte. Ganz absehend von allen positiven Strebungen und Leistungen der heutigen Heilkunde, so ist doch nichts billiger, als von dem Gesetzgeber, welcher die bürgerlichen Berufs - und Erwerbsarten zu classificiren unternimmt, ein äquivalent psychologisches Urtheil über deren sociale Stellung zu verlangen. Wie kann, wie mag man aber schon auf den ersten Blick, die humane, der priesterlichen verwandte, Glaubens- und Vertrauensseite im ärztlichen Verkehre mit den Leidenden, und die darauf bei beiden Seiten beruhende opferwillige Hingebungsweihe überseben, und mit gesetzlichem Schutt überführen, welche für alle Zeiten den himmelweiten Unterschied der ärztlichen Jünger von denen jeder anderen und selbst der höcbst gebildeten respektabelsten und sinnreichsten Technik begründel! Wir wissen Alle, wie viel Routine, persönlich Banausisches und Unwahres die heilkünstlerische Praxis im Leben mit und nach sich führt, und im Lohndienste immer mit sich führen wird, das gibt aber für den Gesetzgeber keinen würdigen Grund ab, dem alten Satze der Sprache und der Logik: „a potiori fit. denominatio"s am ganzen gelehrten Stande untreu zu werden.

Leider musste ich auch das norddeutsche Gewerbegesetz von 1869 , als ich es jüngst nach amtlichem Auftrage durchdacht hatte, wo diese widernatürliche Amalgamirung in der strengsten Consequenz bis auf's Aeusserste durchgeführt ist, mit dem Spruche aus der Hand legen: „tout est perdu, hors de l'argent. " Nach der Vergleichung mit dem Strafgesetzbuche, wo man der "Errungenschaft" der freien Gewerbs- und Frwerbsbewegung, wie es scheint im Einsehen, was intellectuelles und moralisches Verkommen des ärztlichen Hilfstandes für Staat, Geselischaft, Familie Alles auf sich hätte, im strengsten Contraste zu dem obigen "Laissez les faire" einige doppelte Daumenschrauben bereit hält, fügte ich ergänzend hinzu ,et hors de prison." 
Mir will es aber keine kleine psychologische Contradictio in adjecto scheinen, erst unser praktisches Standesleben geradezu in die dichteste banausische Atmosphäre zu verweisen, und, wenn ihm, wie natürlich, von diesen Dünsten die Adern schwellen, mit gesetzlicher Compression derselben sträflich nacbzuhelfen. Ein juridischer Glossator in den Fussstapfen Adelung's würde also gewiss seine Sacbe recht gut machen, wenn er das, was der Sublimat an den "garstigen" Blattern thut: "Blatternputzen", was er am Typhus modelte: „Typhusdrechseln", und was etwa bei meinen Arbeiten am Herzen klappt oder herausspringt, "Herzschlosserei " benamste, und damit Sprache und Gewerbskataster zugleich bereicherte. Möcht' mir ein Patent darauf nehmen, wenn nur nicht unser weiland Collega Rabelais schon vor so und so viel hundert Jahren die Entscheidung der Prozesse nach Würfeln als die sicherste gepriesen hätte! Denn wẹn dem noch so wäre, und dazu noch ein ungünstiger Zufall bei der Wahl des ärztlichen Experten auf einen eifrigen Fürsprech „pro le ge artis nostrae" fiele, so könnte man im Falle eines fehlgeschlagenen Versuchs weit wohlfeiler und zu billigerem Lebensunterhalte ein Patent für das Gefängniss sub titulo: „Fahrlässigkeit geschärft durch Amt und Beruf" davon tragen. Will's also lieber bleiben lassen, indem ich den kleinen Profit und das lange Unmuss in unfreier Luft bei unseren Gewerbsstücken gegen einander abwiege.

Von den neueren Rechtsstaatlern, den Gesetzcopisten aus aller Herren Ländern, lässt sich nichts Neues erwarten. In der That findet sich in dem fiskalischen Taxdecrete Napoleon's von 1811 die Originalausgabe, indem es die ärztlichen Zeugschaften und Expertisen den rein professionellen von Forstwarten, Maurerpalirern u. s. w. in der Entschädigunğ gleichstellt, dagegen seine Freigebigkeit an Notare und Advokaten förmlich verschwendet. Auch im neuen Gewerbegesetze gibt es für die letzteren Classen, welche nicht minder als die der Facultătsbildung entstammlen praktischen Aerzte auf privaten Lohnerwerb angewiesen sind, keinen einzigen ,vorbehaitlichen " Paragraphen, während es mir nicht gelang, auch nur eine einzige geschäftliche Bewegung dieser herauszudenken, welche nicht mit einem Gewerbeparagraphen vorgesehen wäre.

Merkwürdigerweise begegnen wir im Staatsleben dieses dämomischen Mannes von unvergleichlicher Geisteshraft zweierlei Phasen von gesetzlicher Werthschätzung der Heilkunde. Im Geiste des 
freien Griechenthums und seines Hippokrates verklärt mag dem antik consularischen Kopfe ibre Gestalt vorgekommen sein, als er es für eine der ersten gesetzlichen Nothdurften, und zwar gleichzeitig mit dem kirchlichen Friedensschlusse, erkannte, mit dem grossartigen, so vielfach copirten Germinalgesetze von 1803 die ärztlichen Schulen und die ärztliche Ordnung in Frankreich wieder neu anfzurichten, welche von der planimetrischen Republik von 1793 mittelst der "Gewerbefreiheit" in Trümmer gelegt worden waren. In dem Stadium des obgedachten kaiserlichen Decretes liess er bereits mit den Zöglingen seiner jugendlichen Schöpfung die Kronjuristen und Kronfiskale schalten, welche mit der einseitigsten Vorliebe und Ueberschätzung ihrer Bildungssehule und Bildungsverwandten jene an Lohn und Ehre zu kürzen beflissen waren.

Heute sind es die abstracten Grundsätze im Sinne des sogenannten Rechtsstaates, getragen von der Flulh einer irre geleiteten „öffentlichen Meinung “, welche, so lange es nicht öffentliche Fonds betrifft, zwar die „opes" dem ärztlichen Gewerbsmanne wie jedem anderen galant einräumen, von "bonores" aber, welche nicht auch der sträflich infamirteste ärzlliche Schult sein Lebelang nebenher beibehielte, nichts mehr wissen wollen. Gerade an diesem Punkte slösst aber das Gesetz mit der Verweisung in den ausschliesslich um Lobn dienenden Gewerbstand seine schärfste Spitze in das Lebensmark unseres praktischen Berufes. Als alten Administrativbeamten schavdert mich's bei der blossen Vorstellung, wenn ich meinen Stand im äussern Leben, welcher tagtäglich in den intimsten und delicatesten Vertrauensbeziehungen sich bewegt, und in mittelbarer Weise zugleich als Wächter der öffentlichen Sicherheit zu dienen bat, bar an Ehre und spontanem Ehrgefuhl in seinem kritischen Berufe wüsste. Das Gesetz abstrahirt von diesen Integralen, uid lässt die dieser Attribute bis zur Infamie verlustig Gegangenen, wie die notorisch der öffentlichen Sicherheit in Moral und Technik noch so gefährlich Gewordenen, uns als Geschäftscollegen auf dem Halse, gleich als ob der ganze Stand so wenig mehr zu verlieren habe, als dergleichen Auswürflinge. Die gesetzliche Consequenz, niemanden sein ,Handwerk legen" za wollen, ist für diese Sphäre doch etwas zu viel mit dem communistischen "Rechte auf Arbeit" versalzen.

Wenn der neuere Jesuitismus - so curios von dem älteren in Weltblick, Weltverstand, innerer Begeisterung und allseitiger Geistes- 
cultur verschieden - zur Zeit maassgebend wäre, er würde diese Titel und Stufung in der Stellung des ärztlich-praktischen Standes, jedoch dessen „Unterricht" miteingeschlossen, wie aus seinem Herzen geschrieben adoptiren. Der Unterschied wärde nur in Accessorien bestehen, etwas mehr Prison für die seinen Maximen öffentlich Widerspänstigen, aber zur Ausgleichung auch alle Ehren und Zärtlichkeiten für willfährige Werkzeuge. Diese Parallele stelle ich nicht etwa aus blossen Vermuthungen, aus den laufenden Zeitungs - und Tagsgesprächen, sondern auf Grund persönlicher Erlebnisse auf, wo ich sehr "unliebsame" Gelegenheit hatte, die Gesinnungen und Absichten dieser Adepten für unsern Stand in allen ihren Manoeuvern zut beobachten und zu zergliedern. So geschah es in den fünfziger Jahren 4 Jahre lang während meines Einstehens für die statutarischen ärztlichen Haus- und Dienstesrechte als Director des allgemeinen Krankenhauses in Bamberg gegen die damals in floribus des Uebermuthes stebenden dortigen Bannerträger. Hätte ich das kräftigende Andenken an seinen Stifter, den nach altfränkischer Art frommsten und weisesten Fürstbischof Franz Ludwig, und seinen ärztlichen Rathgeber Marcus so weit vergessen können, um mich zum ärztlichen "Gewerbsmann" des Hauses herzugeben, ich hätte unter der Aegide jener Tendenzen alle Scheinehren der Servitut und die fröblicbsten, opulentesten, sorglosesten Tage eines Banausiers haben können, statt der bittersten, von allen Seiten angefeindetsten meines Lebens, mit der einzigen Zufluchtsstätte in dasselbe gute Gewissen für das allgemeine und ständische Wobl, mit welchem jch heute deprimirenden Grundsätzen weltlich-gesetzlichen Ursprungs entgegentrete.

Dass solche Antipoden una Nebenbuhler um den alleinigen oder vorherrschenden Einfluss im Staate, wie moderne Rechtsstaatler und Adepten des neueren Jesuitismus sind, in der grundsätzlichtendentiösen Zurücksetzung des ärztlichen Heilstandes so viel Uebereinstimmendes haben, muss seine tieferen, des Nachdenkens würdigen Grunde haben. Bei den letzteren liegen sie ziemlich offen zu Tage. Sie fürchten von einer wissenschaftlichen Heilkunde und ihren praktischen Jüngern - für hier gleichviel, ob mit mehr zeitlichem Recht oder Unrecht - mehr als von irgend einem andern naturkundigen Zweige, Verbreitung des Materialismus und der Freigeisterei mit einem Uebermuthe des menschlichen Selbstvertrauens auf eigene Kraft. Schwerer aber ist es, sich von den Motiven in der Antipathie der 
Rechtsstaatler, welche doch sonst alle Fortschritte in geistiger Intelligenz und Arbeit preisen, genügende Rechenschaft zu geben, schon weil sie mehr zusammengesetzt sind. Einestheils gebricht es ihnen an den nöthigen Kenntnissen und daher auch au dem besondern Geschmack, um den näheren Zusammenhang vieler esoterischer Strebungen und Forschungen der höhern Heilkunde mit vielen Wurzeln und Adern des staatlichen und gesellschaftlichen Lebens nach Gebühr würdigen zu können. Sie erkennen also im guten Glauben ein physiologisch-ärztliches Sehîeld im letzteren Bereiche nicht an, sie sind durch amtliches. Herkommen einmal nicht anders gewohnt, als: dasselbe für die ausschliessliche Domäne ihrer Schule, ihrer Begriffe und zeitlich obwaltenden Doctrinen zu betrachten. Den Griechen freilich. kam eine solche Trennung der Sebkräfte bei dem öffentlichen Leben noch nicht in den Sinn, sie würden solche für Schielen gehalten haben. Doch, wie sich so manches Unnatürliche in seinen Reactionen zuerst mehr im dunkel Instinctiven als im klaren Erkennen verräth, so geht es auch hier. Die Rechtsstaatler, längst abgeschnitten von der Nabelschnur traditioneller Volkssitten und Volksgesetze, welche den jeweilig zuständigen inneren Fruchtboden der Gesellschaft in der naivsten ungelehrten Weise äusserlich bekannten, fühlen sich mit dunkler Ahnung zum voraus in der ungehemmten Anwendung ihrer versatilen Abstractionen zur staatlichen Organisation und Gesetzgebung von der etwanigen Intervention eines gewichtigen Miturtheilens aus physiologisch-ärztlichem Schosse, welches an einen objectiveren Maassstab gewohnt ist, gefährdet. „Die factisch gegebene, aber veränderliche Capacităt der jeweiligen Volkskräfte in physischen wie sittlichen Beziehungen für gewisse Staatsformen, Institutionen, Gesetze (nationalökonomische voran) nebst ihrer dạuerhaften Vereinbarkeit mit gewissen unveränderlichen physiologischen Grundsätzen richtig, und nicht blos den idealen Werth jener an sich ermessen, d. h. im Grossen physio- und psychologisch individualisiren können und sollen, gleich dem rechten Arzte im Kleinen " - lautet alsogleich eines der strengen, aber natürlichen Gebote, welche jenem Schosse zor Directive entsprungen sind. Nachweisbar sind bäufig genug erst langsam consumirende, dann pestartig grassirende Krankheiten der gesellschaftlichen Moral und materiellen Zustäude die Folge von physiologisch vergriffenen oder nicht objectiv genug vorausbedachten und vorausberechneten Institutionen und staatsgesetzlichen Maassnahmen. 
Trotz unseres mannichfachen Auseinandergehens in politischen und religiösen Ueberzeugungen haben Sie wie ich uns längst in diesem Sinne öffentlich ausgesprochen, und Sie insbesondere haben öfters eine physiologisch-ärztliche Aera für ein primitives autoritätsvolles Mit- und Beirathen in obiger Richtung als unausbleiblich vorausgesagt. Ueber den Zeitpunkt des Eintreffens, über die Art, wie sich diese Umwandlung bewerkstelligen wird, kann man aber verschiedener Ansicht sein. Vorläufig sind dafür noch nicht einmal die inneren Zustände der ärztlichen Gesellschaft bereift und harmonisch genug vorbereitet, andererseits pflegen Wendungen in verjährten eingefleischten Anschauungen der Einseitigkeit nicht rasch, sondern in allmählichen Anwandlungen und Annäherungen zu erfolgen.

Irre ich aber nicht sehr in meinen Vermuthungen, so dürfte es gerade das zeitlich dringlichste Staats- und Gesellschaftsproblem unserer Tage sein, befriedigende Ordnung in der Volksarbeit und ihren niederen Lohnklassen zu schaffen, welches zu der vermissten Annäherung eine der Vermittlungsbrücken baut. Wie dem aber auch werden möge, meine Gedankenweite, nachdem ich seit Jahren mir dieses Thema nach allen Seiten hin und her im Kopfe gewendet habe, vermag nun und nimmermehr abzusehen, wie dasselbe ohne Beirath und Zuthun der somatischen und seelischen Anthropologie organisatorisch bearbeitet oder auch nur balbweg geklärt werden könne. Die Consultation von unzähligen Folianten todter Statistik hat bisher nicht gefördert, - rein juridische Satzungen, bald in Moll, bald in Dur gesetzt, und nach dem Winde der laufenden Zeitverhältnisse zur Abwechslung wieder in einañder umgesetzt, gehen sichtlich an dieser Seuche von „Kampf um die Existenz" spurlos vorüber, und alle ihre Hoffnungen und Verbeissungen sind an ihrer Ausbreitung zu Wasser geworden.

Speyer im August 1871. 